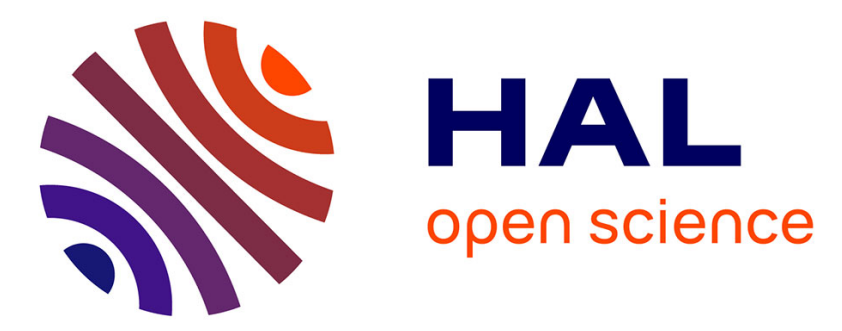

\title{
LPV methods for fault-tolerant vehicle dynamic control
} Olivier Sename, Juan C. Tudon-Martinez, Soheib Fergani

\section{To cite this version:}

Olivier Sename, Juan C. Tudon-Martinez, Soheib Fergani. LPV methods for fault-tolerant vehicle dynamic control. SysTol 2013 - 2nd International Conference on Control and Fault-Tolerant Systems, Oct 2013, Nice, France. hal-00937237

\section{HAL Id: hal-00937237 https://hal.science/hal-00937237}

Submitted on 28 Jan 2014

HAL is a multi-disciplinary open access archive for the deposit and dissemination of scientific research documents, whether they are published or not. The documents may come from teaching and research institutions in France or abroad, or from public or private research centers.
L'archive ouverte pluridisciplinaire HAL, est destinée au dépôt et à la diffusion de documents scientifiques de niveau recherche, publiés ou non, émanant des établissements d'enseignement et de recherche français ou étrangers, des laboratoires publics ou privés. 


\title{
LPV methods for fault-tolerant vehicle dynamic control
}

\author{
Olivier Sename, Juan-Carlos Tudon-Martinez, Soheib Fergani
}

\begin{abstract}
This paper aims at presenting the interest of the Linear Parameter Varying (LPV) methods for vehicle dynamics control, in particular when some actuators may be in failure. The cases of the semi-active suspension control problem and the yaw control using braking, steering and suspension actuators will be presented.

In the first part, we will consider the semi-active suspension control problem, where some sensors or actuator (damper leakage) faults are considered. From a quarter-car vehicle model including a non linear semi-active damper model, an LPV model will be described, accounting for some actuator fault represented as some varying parameters. A single LPV fault-tolerant control approach is then developed to manage the system performances and constraints.

In the second part the synthesis of a robust gain-scheduled $H_{\infty}$ vehicle dynamic stability controller, involving front steering, rear braking, and four active suspension actuators, is proposed to improve the yaw stability and lateral performances. An original LPV method for actuator coordination is proposed, when the actuator limitations and eventually failures, are taken into account. Some simulations on a complex full vehicle model (which has been validated on a real car), subject to critical driving situations (in particular a loss of some actuator), show the efficiency and robustness of the proposed solution.
\end{abstract}

\section{INTRODUCTION}

Automotive vehicles are composed of many interrelated sub-systems, which contribute to the overall improvement in the comfort and safety of vehicle occupants [1], [2]. Analysis, modeling and control of the overall vehicle dynamics is more and more difficult to handle because of stronger requirements in terms of performance and safety, robustness face to external disturbances, uncertainty modeling, sensors and/or actuators faults, etc... This scope has led to numerous research works in Automatic control where various approaches have been employed [3], [4], [5], [6], [7], [8], [9], [10].

This paper highlights the LPV (Linear Parameter Varying) approach whose interest is now proven by many successful applications. Here the problems of semi-active suspension control and vehicle dynamics control (namely yaw control using brake and steering actuators) will be particularly detailed and developed, considering some possible actuator failures. Indeed, while Fault Detection and Isolation (FDI) has led to many contributions in the past, fewer studies have been concerned with the control reconfiguration (parameter adjustment) in the presence of system malfunctions or failures. However, motivated by the aerospace industry it is now admitted that Fault Tolerant Control (FTC) is of

*This work was supported by ANR BLAN INOVE 0308

GIPSA-Lab, Control Systems Dpt, CNRS-Grenoble INP,11 rue des Mathématiques, ENSE3, BP 46, F-38402 St Martin d'Hères cedex, France, olivier.senamedgipsa-lab.grenoble-inp.fr great importance in various industrial sectors like nuclear, process and automotive industries. Let us mention, among others, the survey papers [11], [12]. In that context, we aim at showing two illustrative cases of vehicle dynamics control, namely the suspension control (for comfort and road holding improvements) and the global chassis control (for road handling and safety).

Regarding the problem of control of semi-active suspension, the main challenge is to consider the dissipativity of the damper and the saturation in the synthesis step [4]. If this dissipativity constraint is not taken into account, it is necessary to "saturate" the control input without any performance guarantee, which is referred to as the clipped strategy. In [13] a kind of LPV gain-scheduling anti-windup strategy has been proposed to handle such a constraint, and then in [14], [15] a non linear model of a semi-active damper is rewritten in the LPV form allowing to transform dissipativity of the semiactive damper into a problem of saturation of the control input. This approach will be extended here in the case of some damper malfuntions, incorporating a specific parameter for the loss of damping efficiency.

In the second part, we develop an $H_{\infty}$ Multi-Input MultiOuput (MIMO) gain-scheduled Vehicle Dynamic Control (VDSC) that involves the steering actuators, rear brakes and four active suspension, and aims at enhancing the yaw stability and lateral car performances [16], [17]. The aim of this work is to provide an LPV way towards a smart coordination of the three types of actuators, taking into account the physical limitations and some possible loss of effectiveness of braking and suspension actuators. Some simulation results performed on a full nonlinear vehicle model subject to critical driving situations show that the proposed methodology is effective and robust.

It is worth noting that the simulations presented in that paper are provided using a nonlinear model experimentally validated on the vehicle Renault Mégane Coupé MIPS (Mulhouse) (see [18], [5]), and developed in the framework of the French INOVE project (www.gipsa-lab.fr/projet/inove/)

Following the next section where some related works are mentioned to set the paper context, the use of LPV approaches to deal with FTC design is emphasized in section III. Then section IV is devoted to the suspension control problem and section $\mathrm{V}$ to the vehicle dynamics control problem, subject to actuator malfunctions. Section VI concludes the paper. 


\section{RELATED WORKS}

While this paper will not provide a survey on FTC systems, it is however important to present the problem we are interested in, together with the related works, in order to accurately situate our study, among the FTC, LPV and automotive control approaches.

First, a FTC system aims at keeping the system operation when component malfunctions and/or failures appear [19]. The control objective is then to ensure the closed-loop system stability, and some level of performance, which could be degraded. The most intuitive method is the physical redundancy with duplication of actuator and sensor components, used for systems which high safety and reliability rules. Besides the information redundancy, which is the main concern here, makes use of additional estimation and control algorithms to allow for system surviving.

FTC can be divided in two types: active and passive ones. While the latter aims at designing a controller that will accommodate the fault effects, and could be referred to as a robust controller, the first one includes a reconfiguration mechanism linked to an FDI scheme. In that sense this could be considered as some kind of "adaptive" control. The design issue to be handled mainly concern [11], [12]:

- The design of a FDI procedure including fault detection, isolation and estimation.

- The choice of an high-level reconfiguration strategy that allows for control re-adjustment.

- The design of a reconfigurable controller, namely the choice of specific control structures and approaches.

Most of the works have been concerned with the last issue, for which different strategies have been proposed:

- The synthesis of a bank of controllers with an eventbased switching strategy between nominal, safe and reconfiguration modes.

- The fault hiding approach, where the reconfiguration block takes place in between the faulty plant and the nominal controller, with the objective to keep the system closed-loop performances. This includes the so-called virtual sensor techniques [20], [11].

- The control redesign approach, for which a new controller, accounting for the faulty plant model, is to be synthetized. It is worth noting that, while the reconfiguration must operate in real-time, the design of the controller it-self may be done off-line or on-line according to the considered approach.

This paper is concerned by the latter approach, in the context of the Linear Parameter Varying systems. Less studies have been concerned with such a case, as presented below. Mainly the objective was to extend some existing strategies to the case of LPV systems, which needs to account for larger complexity due to the parameter variations. Let us mention the special issue [21] where most papers have been concerned with FDI for LPV systems as [22]. Concerning FTC for LPV systems, some interesting works have been done in observer design, e.g LPV observer design for state and fault estimation in [23], [24], interval observer for LPV systems in [25], LPV sliding mode observer with fault compensation in [26], Virtual sensor approaches in [27] [28]...

Some studies more related to this paper have concerned the design of LPV FTC where the fault is part of the paramter vector, which allows a fault-scheduling control strategy (i.e an automatic reconfiguration of the controller). Let us mention [29] where some faults corresponding to parameter changes are included in the LPV model description, and according to some estimation, this allows to scheduled the controller w.r.t fault estimation. In [30] a fault parameter corresponding to a loss of hydraulic pressure in an actuator is estimated using an EKF and is used to schedule the controller. Finally in [31], a driver assitance system including steering and braking actuators is designed in the LPV framework and accounts for some loss of efficiency of the actuators that are represented as some scheduling parameters.

Finally, apart from the usual additive fault model (hat has led to many works [32]), the case of sensor and actuator failures is often distinguished due to the application context. For sensor faults, some of the strategies that have been developed include:

- observer-based control with extended state estimation (system state and fault)

- the use of virtual sensor [20]

- the use of sensor switching strategies [33]

In this study, we are interested in actuator malfunctions or failures (which has been considered in many papers as [34] [35] [36] [37] [24]). The focus of this work is to account for actuator limitations in the control reconfiguration scheme. Indeed most of the existing works do consider that the actuator is able to achieve fault compensation by increasing the control gain, which may be not possible if the saturation is reached. The paper will consider both following cases:

- the control of automotive suspension system with semiactive dampers that may be subject to oil leakage

- the vehicle dynamics control, namely the yaw stability control, using steering and braking actuators that could be subject to an efficiency loss and failures.

Such problems have been very few tackled in the literature. Let us mention [38] where faults are considered in the antiroll bar actuator and in the roll rate sensor, and the authors' works [39] where an LPV control of braking/steering control allows to accommodate a loss of effectiveness on the actuator braking thanks to a monitor parameter evaluating the braking efficiency, and [40] where the suspension control problem is considered in the presence of possible damper leakage and where a control reconfiguration strategy is proposed to compensate for the actuator fault.

\section{AN LPV APPROACH FOR FTC}

LPV systems have attracted more and more attention in the last decade since they have shown to be a very interesting extension of the robust control theory to control non linear systems [41]. Basic facts on LMI based $\mathcal{H}_{\infty}$ problem resolution for LPV systems can be found in [42], 
[43], [44], [45], [46], [47], [48], [7]. The interested reader may also find a large number of references in the last decade as mentioned in the recent books [3], [49].

The LPV approach is today known to be well-suited to handle system non linearities by considering them as varying parameters and to make the controller performances varying through the linear introduction of parameters (gainscheduling). It is worth noting that if the non linearities involve state variables the system is referred to as quasi-LPV (and is of course not equivalent to the non linear model). To name but a few examples, it has allowed to account for physical constraints [13] or to represent switching systems [50]. Hence, in the last decade, LPV modelling has been increasingly used to extend classical linear robust control methodology to a larger class of systems, keeping the use of linear tools. Many studies, either theoretical or practical, have been developed in the last few years [51], [52], [53], [54].

LPV models can allow to represent several classes of systems according to the parameter dependency. The usual reprensentation considers that the system matrices depend on the parameter vector in an affine way, which leads to the well know polytopic approach for control design. Other representations may assume polynomial dependency, even rational ones. The specific class of Linear Fractional Representation of LPV systems [55], [56] allows to deal with all the previous cases which is very useful in practical applications [57].

On the other hand, the additional complexity due to the varying parameters requires specific theoretical tools in particular for stability analysis. Then recent studies have concerned model identification [58], stability/stabilization [44] and control design [59], [60], [61], [62].

A LPV state space representation $\Sigma(\theta)$ is usually written as:

$$
\left[\begin{array}{c}
\dot{x} \\
\hline z \\
y
\end{array}\right]=\left[\begin{array}{c|cc}
A(\theta) & B_{1}(\theta) & B_{2}(\theta) \\
\hline C_{1}(\theta) & D_{11}(\theta) & D_{12}(\theta) \\
C_{2}(\theta) & D_{21}(\theta) & D_{22}(\theta)
\end{array}\right]\left[\begin{array}{c}
x \\
w w \\
u
\end{array}\right]
$$

where $x, w$ and $u$ define the state, the exogenous and control input respectively; $z$ and $y$ hold for the controlled output and system measure respectively. $\theta(.) \in \Theta$ is the set of varying parameters that describe a set of systems. $A, B_{1}, B_{2}, C_{1}$, $D_{11}, D_{12} C_{2}, D_{21}$ and $D_{22}$ are real matrices of appropriate dimensions.

If the controller is also assumed to be LPV then the closedloop system is LPV. However the latter may differ from the plant and controller parameter description since some particular representation (as the affine one) may be lost due to the feedback loop. The $\mathcal{H}_{\infty}$ synthesis for LPV systems consists in applying the Bounded Real Lemma to get some set of LMIs (after some relaxation procedures). To cope with the infinite set of LMIs to be solved due to the parameter dependency, several approaches can be used to reduce the problem into a finite number of LMIs, mainly gridding the parameter space, using the Linear Fractional Transformation (LFT) or considering a polytopic approach. The synthesis method considered here is the $H_{\infty}$ quadratic stabilization of LPV systems in the polytopic form, and we invite the reader to refer to particularly interesting studies [47], [44], [45], [7]. Then the applied control is a convex combination of these controllers and can be expressed as follows [63], [52], [5]:

$$
S(\theta)=\sum_{k=1}^{2^{l}} \alpha_{k}(\theta)\left[\begin{array}{ll}
A_{c_{k}} & B_{c_{k}} \\
C_{c_{k}} & D_{c_{k}}
\end{array}\right]
$$

$\left[A_{c_{k}}, B_{c_{k}}, C_{c_{k}} D_{c_{k}}\right]$ representing the controller synthetized at each vertex of the polytope and where,

$$
\sum_{k=1}^{2^{l}} \alpha_{k}(\theta)=1, \alpha_{k}(\theta)>0
$$

We are now interested in providing an unified framework for the design of FTC strategies in the LPV framework. This methodology will be used in both following sections dedicated to suspension and vehicle dynamics control.

Let us then consider an LPV system described by the state space representation:

$$
\Sigma_{L P V}\left\{\begin{array}{l}
\dot{x}=A_{\Sigma}(\lambda(.)) x+B_{\Sigma}(\lambda(.)) \cdot F_{s} \cdot u \\
y=C_{\Sigma}(\lambda(.)) x+D_{\Sigma}(\lambda(.)) u
\end{array}\right.
$$

where $x \in \mathbb{R}^{n}, u \in \mathbb{R}^{n_{u}}$ and $y \in \mathbb{R}^{n_{y}}, A_{\Sigma}, B_{\Sigma}, C_{\Sigma}$ and $D_{\Sigma}$ are real matrices of appropriate dimensions. $\lambda($.) is a varying parameter vector that takes values in the parameter space $\mathcal{P}_{\lambda}$ (a convex set) such that,

$$
\mathcal{P}_{\lambda}:=\left\{\lambda(.):=\left[\begin{array}{lll}
\lambda_{1}(.) & \ldots & \lambda_{l}(.)
\end{array}\right]^{T} \in \mathbb{R}^{l}\right.
$$

and

$$
\left.\lambda_{i} \in\left[\begin{array}{ll}
\underline{\lambda}_{i} & \bar{\lambda}_{i}
\end{array}\right] \forall i=1, \ldots, l\right\}
$$

where $l$ is the number of varying parameters. For sake of readability, $\lambda($.$) will be denoted as \lambda$.

$F_{s}$ is a diagonal matrix that represents the actuator efficiency, i.e.

$$
F_{s}=\operatorname{diag}\left\{\eta_{1}, \ldots, \eta_{n_{u}}\right\}
$$

where $\eta_{i}$ is referred to as the efficiency of the actuator $i$, for $i=1, . ., m$. When $\eta_{i}=1$ the actuator is in nominal conditions. When $0<\eta_{i}<1$ the actuator $i$ is in malfunction, and when $\eta_{i}=0$ the actuator is in failure.

In this paper, we will consider that $\eta_{i}$ are time-varying parameters, and they will be include in $\Theta$ the set of all parameters, as in [30], [31] i.e.

$$
\Theta=\left\{\lambda_{i}, \eta_{i}\right\}, \quad \forall i
$$

On the other hand, while we are interested in the design of LPV control reconfiguration in case of actuator malfunction, we will assume that a FDD (Fault Detection and Diagnosis) scheme is available. Therefore, in all what follows, $\eta_{i}$, $\forall i$, will be considered to be known (even if estimated in practice).

The objective is here to use the LPV framework to design a controller that will be automatically reconfigured in case of actuator malfunction/failure, then to synthesise an LPV controller $S(\theta)$ i.e. $S\left(\lambda_{\star}, \eta_{\star}\right)$. The methodology we will 
follow is the $H_{\infty}$ approach for LPV systems. Thus the plant model will be aggregated with weighting functions that represents the required closed-loop performances and actuator limitations. Following some author works [64], [16], we will consider that the weighting functions are parameter dependant in order to account for closed-loop real-time performance adaptation according to:

- system non linearities as in [10]

- actuator limitations as in [7]

- actuator malfunctions/failures that could lead to performance degradation and require the reconfiguration of the actuator coordination for multi-input systems.

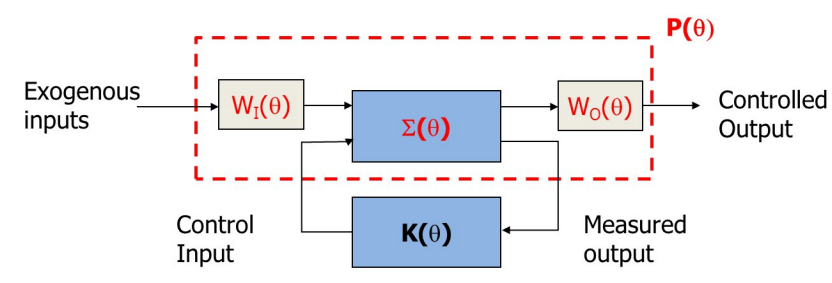

Fig. 1. LPV General Control Configuration

We will then denote $W_{I}(\theta)$ and $W_{O}(\theta)$ some input and output parameter dependent weighting functions. The interconnection of the plant model $\Sigma_{L P V}$ together with the weighting functions $W_{I}(\theta)$ and $W_{O}(\theta)$, leads to the LPV generalized plant $P(\theta)$ (see Fig 1):

$$
P(\theta):\left[\begin{array}{c}
\dot{x} \\
\hline z \\
y
\end{array}\right]=\left[\begin{array}{c|cc}
A(\theta) & B_{1}(\theta) & B_{2}(\theta) \\
\hline C_{1}(\theta) & D_{11}(\theta) & D_{12}(\theta) \\
C_{2}(\theta) & D_{21}(\theta) & D_{22}(\theta)
\end{array}\right]\left[\begin{array}{c}
x \\
\hline w \\
u
\end{array}\right]
$$

A. An LPV adaptive control for FTC

It is usual in $H_{\infty}$ control to include the control input among the set of controlled outputs, in order to take into account the actuator limitations. We will use this degree of freedom in order to specify some augmentation of the control gain in case of actuator malfunction. This a way to provide fault compensation as in [24]. A possible choice is to add the controlled output:

$$
z_{u}=W_{u}\left(F_{s}\right) \cdot u
$$

where $W_{u}$ is chosen to adapt the required control gain to the actuator efficiency, allowing to penalize the control input when the actuator is in malfunction. Thus for each input $u_{i}$, $\forall i$, we may choose:

$$
z_{u_{i}}=\frac{1}{\eta_{i}} W_{u_{i}}(s) \cdot u_{i}
$$

where $W_{u_{i}}(s)$ is chosen according to the $i-t h$ actuator bandwidth and nominal saturation.

Once $P(\theta)$ is obtained an LPV controller $K(\theta)$ can be computed. The next step is the real-time implementation of such a controller that requires to define on-line each parameter $\eta_{i}$.
Remark 1: - It is worth noting that other weighting functions could depend on the efficiency parameter set, in order, for instance, to degrade the performance requirements on tracking performances ...

- Of course the way to increase control gain to compensate for actuator malfunction is only possible if the actuator limitations are not reached. As proposed later for semi-active suspension, these limitations should be in practice taken into account to propose a solution that can be implemented.

\section{B. An LPV approach for actuator coordination in view of} FTC

The method that we will propose derives from previous authors' work as [65], [16]. The aim is to coordinate the actuators of a MIMO system in order to avoid an over use of all actuators, to account for the inherent actuator limitations, and to alleviate disturbances due to actuator malfunctions. The originality stands in the controller structure that is chosen of the form:

$$
K_{s}(.):=\left\{\begin{array}{l}
\dot{x}_{c}(t)=A_{c}(.) x_{c}(t)+B_{c}(.) y(t) \\
u(t)=\underbrace{U(.) C_{c}^{0}(.)}_{C_{c}(.)} x_{c}(t)
\end{array}\right.
$$

with

$$
U(\rho)=\left(\begin{array}{cccc}
\rho_{1} & 0 & 0 & 0 \\
0 & \rho_{2} & 0 & 0 \\
0 & 0 & \ddots & 0 \\
0 & 0 & 0 & \rho_{n_{u}}
\end{array}\right)
$$

where $\rho_{i}$ is function of $\left\{\eta_{1}, \ldots, \eta_{n_{u}}\right\}$, for all $i$.

The choice of the parameters $\rho_{i}$, for $i=1, \ldots, n_{u}$ can allow to activate or not the control action, as well as to attenuate (or weight) it. As done in [16] for a braking system with left/right active brakes that needs to act when the vehicle is oversteering (or uncersteering), a simple convex combination with $\sum_{i=1}^{n_{u}} \rho_{i}=1$ may provide an efficient control allocation (with an adequate distribution of the control actions on the different actuators). This will be illustrated for the LPV FTC control for vehicle dynamics.

\section{LPV FOR FTC SUSPENSION CONTROL}

\section{A. Problem Formulation}

Because of the higher demands of the automotive industry in comfort and safety of road vehicles, the development of intelligent suspension systems has gained importance during last years. As part of these innovative suspensions, semiactive shock absorbers are efficient actuators to improve passengers comfort and car road holding as well [66]. The comfort is monitored by the vehicle body motion transmitted through the suspension, while the road holding is interpreted as the suspension capability to maintain the wheel-road contact.

As shown in recent studies [66] [4], the control design for semi-active dampers is complex due to the dissipativity constraint on the damper (which is indeed a state dependent 
saturation [67]). Moreover, if the damper is subject to faults, e.g. oil leakages, the development of control techniques with fault-tolerance features is required to maintain the reliability of the automotive suspension system (comfort and road holding).

Actual FTC [68], [69], [38] are proposed for active suspensions only, and then do not need to handle the dissipativity constraint of the damper, i.e. they have more operating freedom but their implementations are less attractive because their high cost. In addition, none of the existing FTC considers the saturation constraint in its design when the shock absorber is faulty. When an oil leakage occurs in a shock absorber, inherently its damping capability is reduced; this available damping force must be considered by the controller in order to avoid an impractical solution. If the saturation constraint is not considered to control a failed actuator that cannot be replaced, i.e. in absence of redundancy of actuators as in an automotive suspension system, the implementation could be compromised.

Figure 2 shows the Force-Velocity (FV) map of a semiactive damper subject to different leakages, by using the same road excitation. For a healthy semi-active shock absorber, the available damping force (low and high level) is greater than a faulty damper and consequently the deflection motion decreases, i.e. the maximum velocity of deflection is lower. When the damper has an oil leakage, the available damping force is reduced (namely the saturation constraints do change) and the maximum velocity to achieve low and high damping level is increased, e.g. when the fault reduces $30 \%$ of the damping force, the maximum deflection velocity is increased around $0.5 \mathrm{~m} / \mathrm{s}$ in both damping levels.

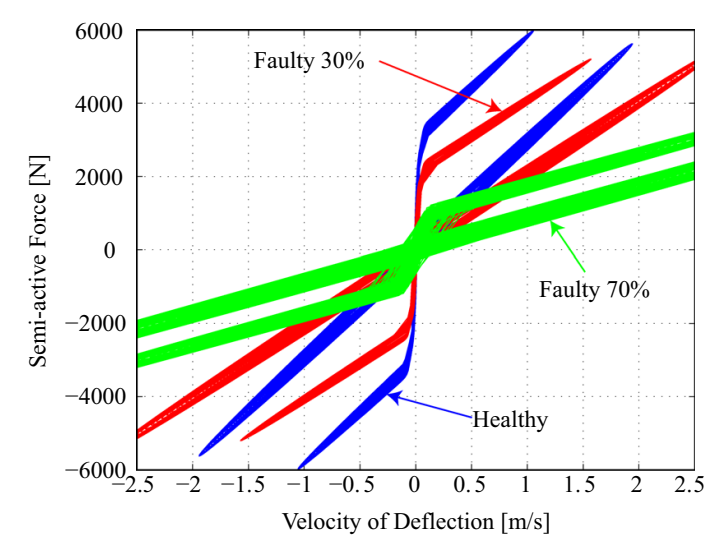

Fig. 2. Force-Velocity map of a semi-active damper (low and high damping) subject to different leakages.

In model-based control approaches, the physical constraints of a semi-active damper must be included in the control design to avoid an erroneous damping solution, Fig. 3 displays some examples of control that do not fulfill these constraints:

- If the required force is outside of the available force domain of the semi-active damper (magenta circle in Fig. 3), the controller is erroneously designed to add and dissipate energy like an active damper.

- If the required force is greater than the maximum possible damping force and/or lower than the minimum possible damping force, orange square in Fig. 3, the control objectives are compromised even if the controller design guarantees the dissipativity constraint.

- If the damper has an oil leakage, and the saturation constraint is not adapted, the required force could be outside of the range of the "real" faulty force (even if it is inside of the range of the healthy force). In this case, the control performances are not ensured if some fault information is not included into the control design.

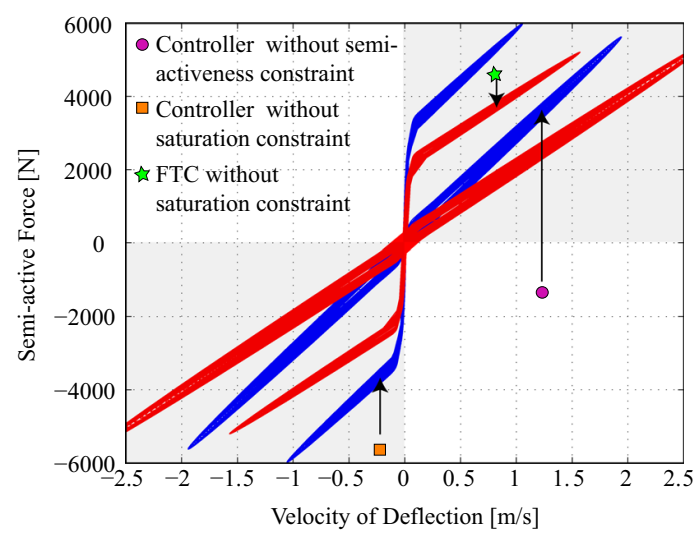

Fig. 3. Constraints in the control of a semi-active damper.

In this study, it is proposed an FTC based on LPV that includes the damper constraints to fully exploit the semiactiveness of the shock absorber in a practical implementation, and thus achieve the best possible performances even when the actuator is faulty.

1) Problem Definition: The semi-active damper model is here assumed of the following form as [70], [71]:

$$
F_{s a}=\underbrace{b_{1}\left(\dot{z}_{s_{i}}-\dot{z}_{u s_{i}}\right)+b_{2}\left(z_{s_{i}}-z_{u s_{i}}\right)}_{\text {passive }}+\underbrace{I \cdot f_{c} \cdot \rho}_{\text {semi-active }}
$$

where $I$ is the electric current to control the semiactive force based on the desired performances and $\rho=$ $\tanh \left[a_{1} \dot{z}_{\text {def }}+a_{2} z_{d e f}\right] \in[0,1]$ represents the nonlinearities of the shock absorber. For $I=0, F_{s a}$ reduces to the passive damping force of the suspension system.

Consider now an oil leakage on a semi-active damper, which induces a lack of force modeled as:

$$
\bar{F}_{s a}=\alpha F_{s a}
$$

where $\bar{F}_{s a}$ represents the faulty force expressed as a reduction of the nominal semi-active force and, $\alpha \in[0,1]$ is the oil leakage degree, e.g. $\alpha=0.7$ means that the damping force will be of $70 \%$ of $F_{s a}$ due to a lost force of $30 \%$.

The vertical dynamics of a Quarter of Vehicle model, including a faulty semi-active damper, is then considered in this study as the following state-space representation: 


$$
\begin{aligned}
\underbrace{\left[\begin{array}{c}
\dot{z}_{s} \\
\ddot{z}_{s} \\
\dot{z}_{u s} \\
\ddot{z}_{u s}
\end{array}\right]}_{\dot{x}}= & \underbrace{\left[\begin{array}{cccc}
0 & 1 & 0 & 0 \\
-\frac{k_{s}+\alpha b_{2}}{m_{s}} & -\frac{\alpha b_{1}}{m_{s}} & \frac{k_{s}+\alpha b_{2}}{m_{s}} & \frac{\alpha b_{1}}{m_{s}} \\
0 & 0 & 0 & 1 \\
\frac{k_{s}+\alpha b_{2}}{m_{u s}} & \frac{\alpha b_{1}}{m_{u s}} & -\frac{k_{s}+k_{t}+\alpha b_{2}}{m_{u s}} & -\frac{\alpha b_{1}}{m_{u s}}
\end{array}\right]}_{A} \underbrace{\left[\begin{array}{c}
z_{s} \\
\dot{z}_{s} \\
z_{u s} \\
\dot{z}_{u s}
\end{array}\right]}_{x} \\
& +\underbrace{\left[\begin{array}{cc}
0 & 0 \\
0 & \frac{-\alpha \cdot \rho f_{c}}{m_{s}} \\
0 & 0 \\
\frac{k_{t}}{m_{u s}} & \frac{\alpha \cdot \rho f_{c}}{m_{u s}}
\end{array}\right]}_{B} \underbrace{\left[\begin{array}{c}
z_{r} \\
I
\end{array}\right]}_{u} \\
\underbrace{\left[\begin{array}{l}
y_{1} \\
y_{2}
\end{array}\right]}_{y}= & \underbrace{\left[\begin{array}{cccc}
1 & 0 & -1 & 0 \\
0 & 1 & 0 & -1
\end{array}\right]}_{C}\left[\begin{array}{c}
z_{s} \\
\dot{z}_{s} \\
z_{u s} \\
\dot{z}_{u s}
\end{array}\right]
\end{aligned}
$$

By estimating the parameter $\alpha$ by an FDD module, and computing $\rho$ directly from the measurements, it is possible to create a generalized LPV plant strictly proper of the form (1), with $\theta:\{\alpha, \rho\}$, as:

$$
\left[\begin{array}{c}
\dot{\xi} \\
\hline z_{\infty} \\
y
\end{array}\right]=\left[\begin{array}{c|cc}
\mathcal{A}(\theta) & \mathcal{B}_{1}(\theta) & \mathcal{B}_{2} \\
\mathcal{C}_{\infty}(\theta) & \mathcal{D}_{1_{\infty}}(\theta) & \mathcal{D}_{2_{\infty}} \\
\mathcal{C} & 0 & 0
\end{array}\right]\left[\begin{array}{c}
\xi \\
w \\
u_{c}
\end{array}\right]
$$

in order to design an LPV FTC (active FTC with scheduling reconfiguration) of the form (2) with $S(\theta)=\sum_{i=1}^{2^{i}} \alpha_{i}(\theta) S_{i}$ by appropriately choosing the gains $S_{i}, i=1, \ldots, 2^{i}$ such that the closed-loop system be asymptotically stable in all parameter variations and the $H_{\infty}$ control performances fulfill with the constraints of a faulty damper and thus avoid impractical solutions.

\section{B. LPV FTC in a Semi-Active Suspension}

By considering the vertical dynamics in a $Q o V$ model, the semi-active damping force represents the key element to isolate vibrations caused from road irregularities. When the damper partially fails, the available damping force is lower and the control performances must be adapted to these new damper conditions.

1) LPV Modeling: Based on the nonlinear QoV dynamics depicted in eq. (14), an LPV model structure can be expressed as:

$$
\begin{aligned}
& \dot{x}=A(\alpha) \cdot x+B(\alpha, \rho) \cdot u \\
& y=C \cdot x
\end{aligned}
$$

In order to make the control input matrix parameter independent and get a proper structure for the $L P V$ based controller synthesis [13], the state-space model in (16) is augmented by adding a low-pass filter $W_{\text {filter }}=\omega_{f} /\left(s+\omega_{f}\right)$ with state $x_{f}$ and matrices $\left(A_{f}, B_{f}, C_{f}\right)$. The resulting new LPV model is given by:

$$
\begin{aligned}
{\left[\begin{array}{c}
\dot{x} \\
\dot{x}_{f}
\end{array}\right] } & =\left[\begin{array}{cc}
A(\alpha) & B_{1}(\alpha, \rho) C_{f} \\
0_{1 \times 4} & A_{f}
\end{array}\right]\left[\begin{array}{c}
x \\
x_{f}
\end{array}\right]+\left[\begin{array}{cc}
B_{2} & 0_{4 \times 1} \\
0 & B_{f}
\end{array}\right] u \\
y & =\left[\begin{array}{ll}
C & 0
\end{array}\right]\left[\begin{array}{c}
x \\
x_{f}
\end{array}\right]
\end{aligned}
$$

where $B_{1}$ is the column matrix of $B$ associated to $I$ and $B_{2}$ is the column matrix of $B$ associated to $z_{r}$ in (14).
Based on [15], it is possible to saturate the controller output into the admissible range of manipulation by using an additional scheduling parameter, such that the states in (17) are rewritten as:

$$
\begin{aligned}
{\left[\begin{array}{c}
\dot{x} \\
\dot{x}_{f}
\end{array}\right]=} & {\left[\begin{array}{cc}
A(\alpha)+A_{21} \cdot \rho_{2} \cdot A_{22} & B_{1}\left(\rho_{1}\right) C_{f} \\
0_{1 \times 4} & A_{f}
\end{array}\right]\left[\begin{array}{c}
x \\
x_{f}
\end{array}\right] } \\
& +\left[\begin{array}{cc}
B_{2} & 0_{4 \times 1} \\
0 & B_{f}
\end{array}\right]\left[\begin{array}{l}
z_{r} \\
u_{c}
\end{array}\right]
\end{aligned}
$$

where the matrixes $A_{21}=\left[\begin{array}{lllll}0 & -\frac{I_{0} \cdot f_{c}}{m_{s}} & 0 & \frac{I_{0} \cdot f_{c}}{m_{u s}}\end{array}\right]^{T}$ and $A_{22}=\left[\begin{array}{llll}a_{2} & a_{1} & -a_{2} & -a_{1}\end{array}\right]^{T}$ are used to bound $I \in$ $\left[I_{\min }, I_{\max }\right]$ such that $I_{0}$ is the average between these limits of actuation.

2) Scheduling Parameters: In this study, the QoV model used to synthesize the LPV FTC is parameter dependent. The varying parameters $\rho_{1}$ and $\rho_{2}$ allow to ensure that the suspension control respects the semi-activeness and saturation damper constraints, respectively. As shown in Fig. 2, these actuator constraints change if the damper is faulty, such that $\rho_{1}$ and $\rho_{2}$ depend on the efficiency of the actuator as:

$$
\begin{array}{lll}
\rho_{1}=\alpha \cdot \rho \cdot \frac{\tanh \left(C_{f} x_{f} / I_{0}\right)}{C_{f} x_{f} / I_{0}} & \in[-1,1] \\
\rho_{2}=\frac{\alpha \cdot \rho}{A_{22} x} & \in[0,1]
\end{array}
$$

The LPV system then includes 3 time-varying parameters. The varying parameter $\alpha$, estimated by an FDD strategy, allows an on-line adaptation of the semi-active damper when this has a leakage. Based on parity-space theory, it is possible to generate a residual with decoupling between disturbances and faults, i.e. sensitive to the leakage and insensitive to the bounded exogenous road disturbances. According to [40], the faulty damping force $\bar{F}_{s a}$ due to a damper leakage can be estimated by:

$$
\widehat{\bar{F}}_{s a}(t)=\left[\mathcal{W} \mathcal{G}_{F}^{l}\right]^{+}\left(r(t)-\mathcal{W} \mathcal{G}_{F}^{r}\left[\begin{array}{c}
\hat{\bar{F}}_{s a} \\
\vdots \\
\widehat{\bar{F}}_{s a}^{(s)}
\end{array}\right]\right)
$$

where, the operator $[\cdot]^{+}$stands for the Moore Penrose pseudo inverse. The matrix $\mathcal{W}$ is the parity matrix to generate the residues $r(t)$ that decouples the faults from disturbances and uncertainties, given by:

$$
\begin{aligned}
r(t)=\mathcal{W}\left(\left[\begin{array}{c}
y \\
\dot{y} \\
\ddot{y} \\
\vdots \\
y^{(s)}
\end{array}\right]-\mathcal{G}_{I}\left[\begin{array}{c}
I \\
\dot{I} \\
\ddot{I} \\
\vdots \\
I^{(s)}
\end{array}\right]\right)=\mathcal{W} \mathcal{G}_{F}\left[\begin{array}{c}
\bar{F}_{s a} \\
\dot{\bar{F}}_{s a} \\
\ddot{F}_{s a} \\
\vdots \\
\bar{F}_{s a}{ }^{(s)}
\end{array}\right] \\
=\mathcal{W}\left[\mathcal{G}_{F}^{l} \mid \mathcal{G}_{F}^{r}\right]\left[\begin{array}{c}
\bar{F}_{s a} \\
\bar{F}_{s a} \\
\vdots \\
\bar{F}_{s a}{ }^{(s)}
\end{array}\right]
\end{aligned}
$$

by considering an horizon $s$ associated to the $s-t h$ time derivative; the matrixes $\mathcal{G}_{I}$ and $\mathcal{G}_{F}$ distribute the inputs $I$ 
and $F_{\delta}$ on the system. Because a perfect decoupling is quite difficult to achieve, the null space matrix $\mathcal{W}$ can be solved by an optimization problem as in [40], [72].

Once the faulty force is estimated by the FDD, $\alpha$ can be easily computed by using a virtual sensor of the normal damping force, as:

$$
\alpha \approx \sqrt{\frac{\sum_{i=1}^{N} \hat{\bar{F}}_{s a_{i}}^{2}}{\sum_{i=1}^{N} F_{s a_{i}}^{2}}} \in[0,1]
$$

Figure 4 shows an example of how a faulty damper affects the suspension performance. An increment of the damper leakage $\alpha$ causes:

- An increment of the vertical chassis acceleration $\ddot{z}_{s}$ close to the frequency of resonance of the sprung mass (around $1.5 \mathrm{~Hz}$ ), affecting the comfort at low frequencies. The comfort deterioration can also be quantified by the increment of the vertical displacement of the sprung mass $\left(z_{s}\right)$; in this case, the comfort is deteriorated up to $300 \%$ at low frequencies.

- An increment of the vertical displacement of the unsprung mass $z_{u s}$ close to its natural frequency (around $8.5 \mathrm{~Hz}$ ). The road holding performance is deteriorated up to $250 \%$ when the damping force is faulty.

- An increment in the suspension deflection $z_{\text {def }}$ mainly close to the frequencies of resonance of the sprung and unsprung mass. This inappropriate increment of motion affects the time-life of all suspension components.

The main idea of the proposed LPV FTC in the semiactive suspension is to provide the best possible trade-off between road holding and passengers comfort, by using the available damping force, such that the scheduling parameters $\rho_{1}$ and $\rho_{2}$ are fault-adaptive. For instance, Figure 5 shows (in open-loop) how the suspension performances of a faulty damper improve with a change in the electric current (from 1 to $3 \mathrm{~A}$ ); however inherently they are not the same that in the healthy case because the lack of force. In absence of saturation, the control output could demand more than the physical limits of the actuator to reject completly the faults, such as $8 \mathrm{~A}$ in a semi-active damper where the range of electric current is from 0 to $3 \mathrm{~A}$. This is possible thanks to the available damper model; another solution is to take into account the actuator limitations by adding the control input among the set of controlled outputs.

3) $L P V / H_{\infty}$ control synthesis for FTC: Here the proposed LPV FTC uses a varying parameter $(\alpha)$ associated to the fault to schedule the suspension actuator work according to new damping characteristics. Because the suspension performances depend directly on the fault parameter $\alpha$, as is shown in Figure 4, this scheduling parameter is used to define parameter dependent weighting functions allowing to modify on-line the performance specifications according to the state of health of the damper. The LPV synthesis framework is shown in Figure 6, with $W_{z_{s}}=\alpha k_{z_{s}} \frac{s^{2}+2 \zeta_{11} \omega_{11} s+\omega_{11}{ }^{2}}{s^{2}+2 \zeta_{12} \omega_{12} s+\omega_{12}{ }^{2}}$ (focused on passengers comfort at low frequencies), $W_{z_{u s}}=$ $\alpha k_{z_{u s}} \frac{s^{2}+2 \zeta_{21} \omega_{21} s+\omega_{21}{ }^{2}}{s^{2}+2 \zeta_{22} \omega_{22} s+\omega_{22}{ }^{2}}$ (focused on road holding at high frequencies) and $W_{r}=k_{z_{r}} \frac{\omega_{r}}{s+\omega_{r}}$ (road profile). Thus, in a
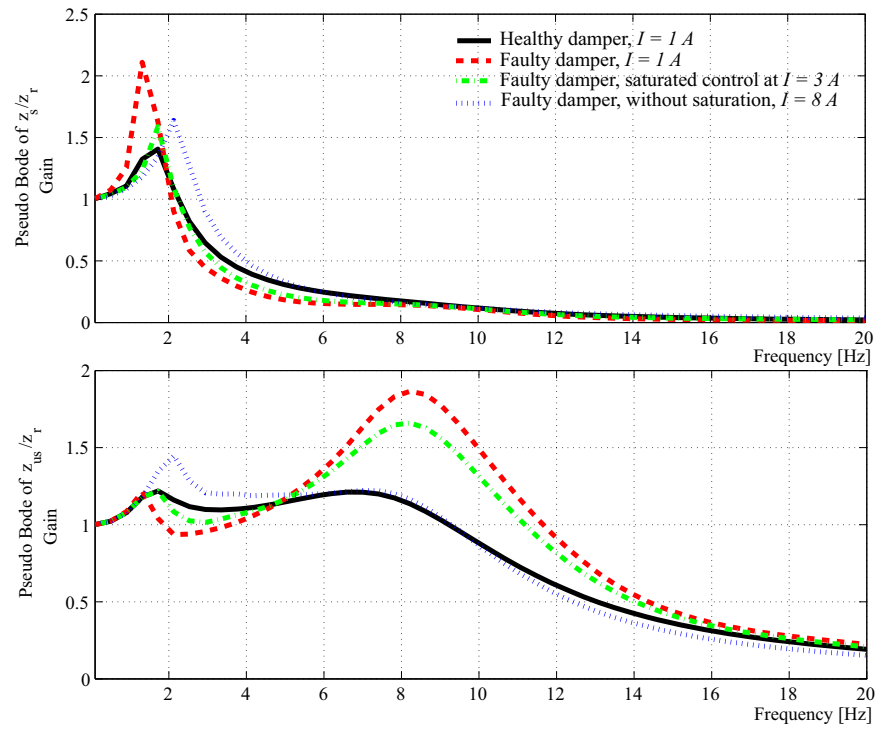

Fig. 5. Semi-active suspension performances at different manipulations, by considering a fault $\alpha=0.5$.

fault case the gain of weighting functions is decreased to increase its inverse value used in the $H_{\infty}$ design.

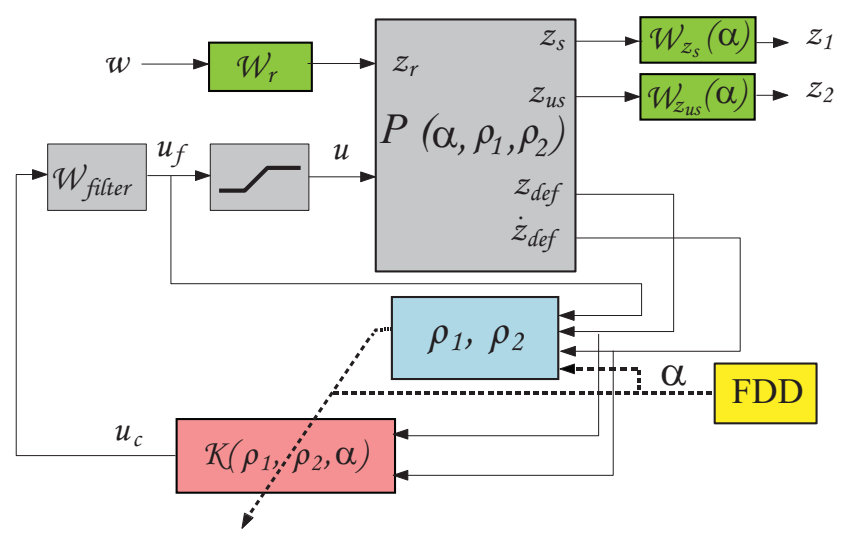

Fig. 6. LPV FTC configuration for synthesis.

The corresponding generalized plant $P(\theta)$ is a 3 linear parameter depending system as follows:

$$
\left[\begin{array}{c}
\dot{\xi} \\
\hline z_{\infty} \\
y
\end{array}\right]=\left[\begin{array}{c|cc}
\mathcal{A}\left(\alpha, \rho_{1}, \rho_{2}\right) & \mathcal{B}_{1} W_{r} & \mathcal{B}_{2} \\
\hline \mathcal{C}_{\infty}\left(\alpha, \rho_{1}, \rho_{2}\right) & 0 & 0 \\
\mathcal{C} & 0 & 0
\end{array}\right]\left[\begin{array}{c}
\xi \\
w \\
u_{c}
\end{array}\right]
$$

where $\xi=\left[\begin{array}{ll}\chi_{\text {vert }} & \chi_{w}\end{array}\right]^{T}$ such that $\chi_{\text {vert }}$ are the states in the vertical dynamics of the augmented $Q o V$ model of (18) and $\chi_{w}$ are the vertical weighting functions states, $z_{\infty}=$ $\left[\begin{array}{ll}z_{1} & z_{2}\end{array}\right]^{T}, y=\left[\begin{array}{ll}z_{\text {def }} & \dot{z}_{\text {def }}\end{array}\right]^{T}$ and $u_{c}=u_{i j}^{\mathcal{H}}$.

The proposed LPV $/ \mathcal{H}_{\infty}$ robust controller is synthesized by solving the LMI problem for a polytopic set of parameters. Because the 3 varying parameters are bounded $(\alpha \in[0,1]$, $\rho_{1} \in[-1,1]$ and $\left.\rho_{2} \in[0,1]\right)$, the global LPV-FTC is a convex combination of 8 local controllers expressed as in (2). Since the LMI problem is solved at each vertex of the polytope formed by the limit values of the varying 

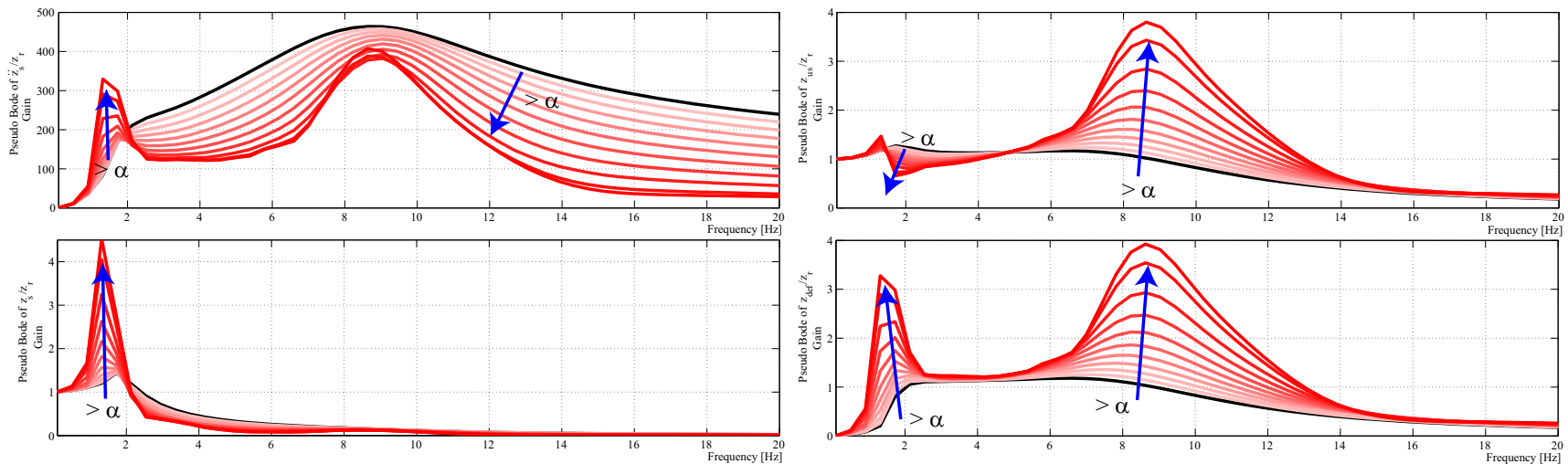

Fig. 4. Semi-active suspension performances at different faulty conditions, $\alpha \in[0.05,1]$. Open-loop anaylsis at constant $I=1.5 A$, where $I \in[0,3]$.

parameters, the stability will be guaranteed for all trajectories of the varying parameters.

4) Simulation Results: Time domain simulations are performed on the LPV QoV model given by (14) that includes a faulty semi-active damper. In order to compare the performance of the proposed LPV-FTC, a classical semi-active LPV controller without fault tolerance features, denoted as "LPV nominal", is used as benchmark.

The scenario consists on a $3 \mathrm{~cm}$ bump on the wheel from $t=1 \mathrm{~s}$ to $t=1.5 \mathrm{~s}$. The damper leakage, $50 \%$ of reduction of the nominal damping force $(\alpha=0.5)$, occurs at $t=0$. Figure 7 shows that the sprung mass displacement is reduced whit the LPV-FTC whit respect to (w.r.t.) the LPV nominal controller; by using the RMS of this signal, the comfort performance is improved $16.3 \%$ and the setling time is reduced 2 seconds. Inherently, the sprung mass displacement is lower when the damper is free of faults, i.e. although the LPV-FTC is better than the LPV nominal controller, the LPVFTC cannot retrieve the same performance as the nominal case because the damping force has more limitations.

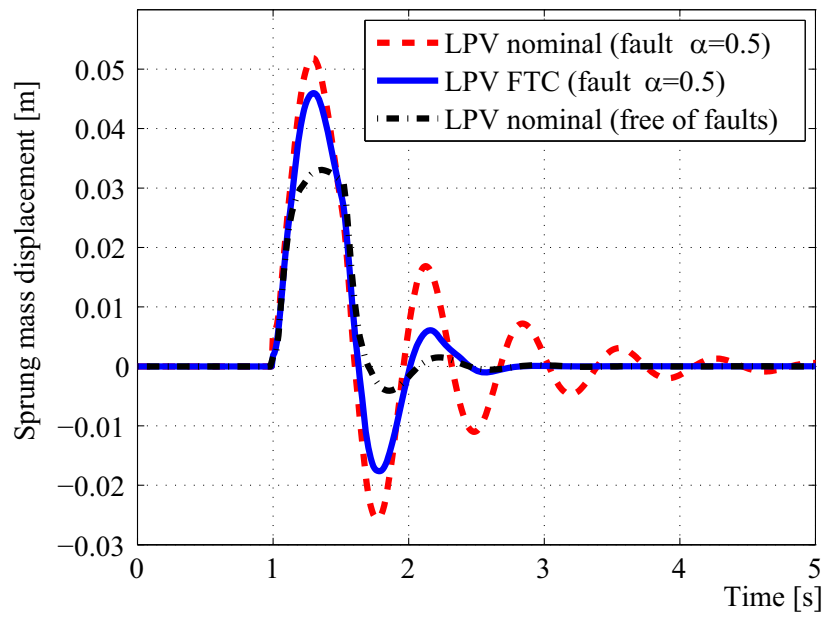

Fig. 7. Comfort performance: Transient response of the sprung mass displacement.

Similarly, the suspension displacement is lower whit the LPV-FTC, Figure 8. The relative displacement is reduced
$27.7 \%$ by using the RMS, i.e. the road holding is improved a lot by the LPV-FTC, which reduces the setling time 2.5 seconds.

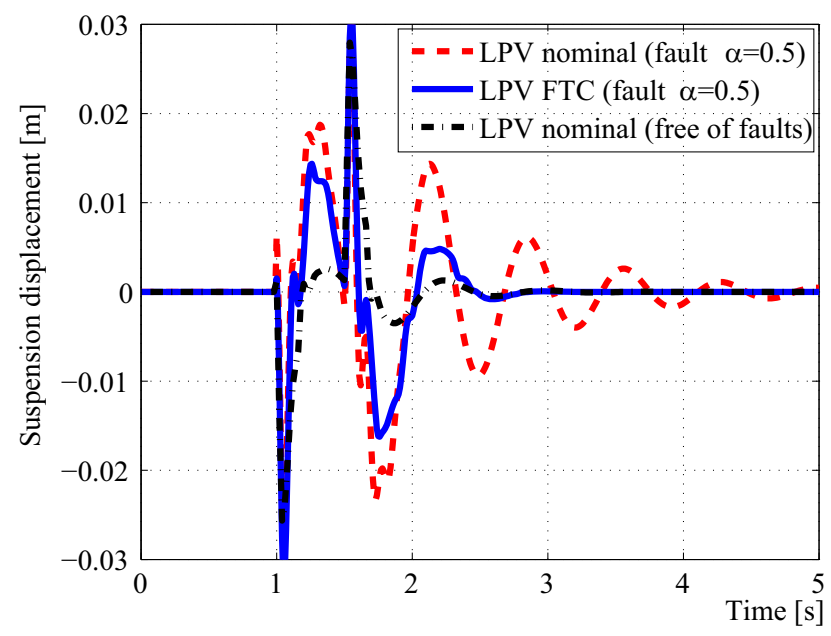

Fig. 8. Road holding performance: Transient response of the relative displacement among the sprung and unsprung mass.

Figure 9 shows the controller output in each case; note that when the damper is free of faults, the LPV controller only acts when the vehicle passes on the bump, i.e. at time $t=1 \mathrm{~s}$ and $t=1.5 \mathrm{~s}$ when it exists an exogenous road input. When the damper is subject to the fault, the LPV nominal controller can not schedule the malfunction, thus the manipulation (electric current) only appears in presence of the exogenous road input. Conversely, the LPV-FTC input current changes for long to schedule the damper leakage and achieve the best possible performances at every moment.

\section{LPV FTC FOR VEHICLE DYNAMICS CONTROL}

In this section we aim at showing that the LPV approach is an interesting tool to manage simultaneously critical driving situations due to road/vehicle conditions as well as actuator malfunctions. The considered framework to illustrate such an interest is the yaw control using 3 types of actuators, namely suspension, steering and braking control. While lots of studies have been dedicated to yaw control, in particular using 


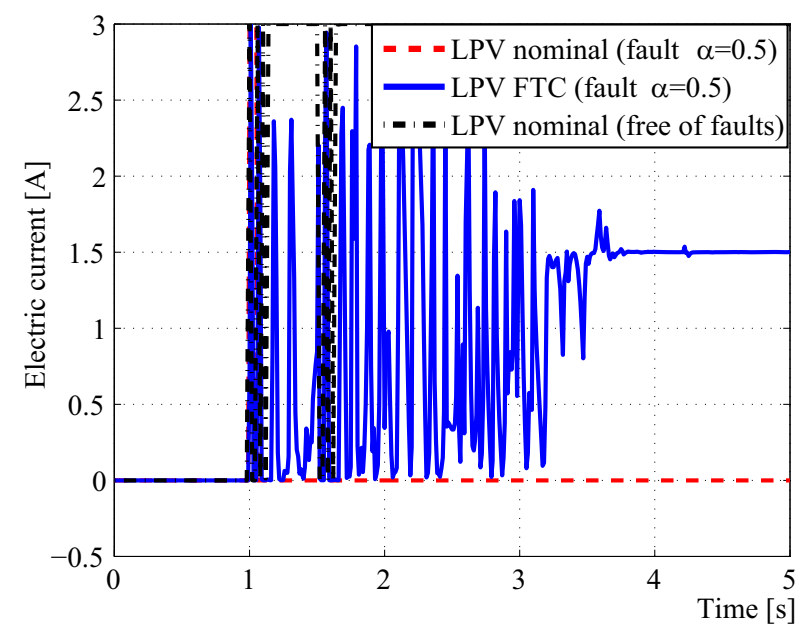

Fig. 9. Controller output in the semi-active suspension.

steering/braking actuators as explained in [17], fewer have considered the 3 actuator types. Among then, the authors have providing several methodologies as in [73], [74], [75], [76]. While all that works have considered different cases in term of actuator coordination and/or emergency situations, no one has accounted for actuator malfunctions, which is the main objective here.

A new LPV/H$H_{\infty}$ MIMO Global Chassis Controller (GCC) that aims at handling the lateral dynamic control, i.e. the yaw control, and improving vehicle stability subject to critical driving situation is proposed using the front active steering, rear braking and active suspension actuators (see Fig.10). This strategy is scheduled by 3 parameters $\left(\rho_{b}, \rho_{s}\right.$ and $\left.\rho_{l}\right)$. Indeed, a special monitoring system is defined to evaluate how a driving situation is dangerous and to account for braking/suspension actuator failures. The control structure is then defined to be fault tolerant. This means that it can handle one actuator failure by changing the configuration of control on line. The whole strategy provides a maximum help to the driver by avoiding accidents during emergency situations. The smart progressive activation of the actuators is the key of performance and safety improvement.

It is worth noting that the controllers are derived thanks to $\mathrm{LPV} / \mathcal{H}_{\infty}$ methodology. This framework allows to smoothly tune the control performances thanks to the scheduling parameters $\rho_{b}$ et $\rho_{s}$, guaranteeing internal stability (avoiding switching) and ensuring $\mathcal{H}_{\infty}$ performances.

\section{A. A New Fault Tolerant Scheduling strategy}

1) Control adaptation to critical driving situations and braking actuator malfunction: Two scheduling parameters $\rho_{b}$ and $\rho_{s}$ will be used to coordinate the actuators and provide a hierarchical use of the 3 VDSC actions (steering, braking and active suspension). When a dangerous situation is detected, the GCC gives a torque reference to the braking system (that avoids slipping thanks to the ABS local controller), and if the braking system is not efficient enough and is not able to stabilize the vehicle (e.g. in case of low adherence or braking failure), the steering system is activated, and the suspension

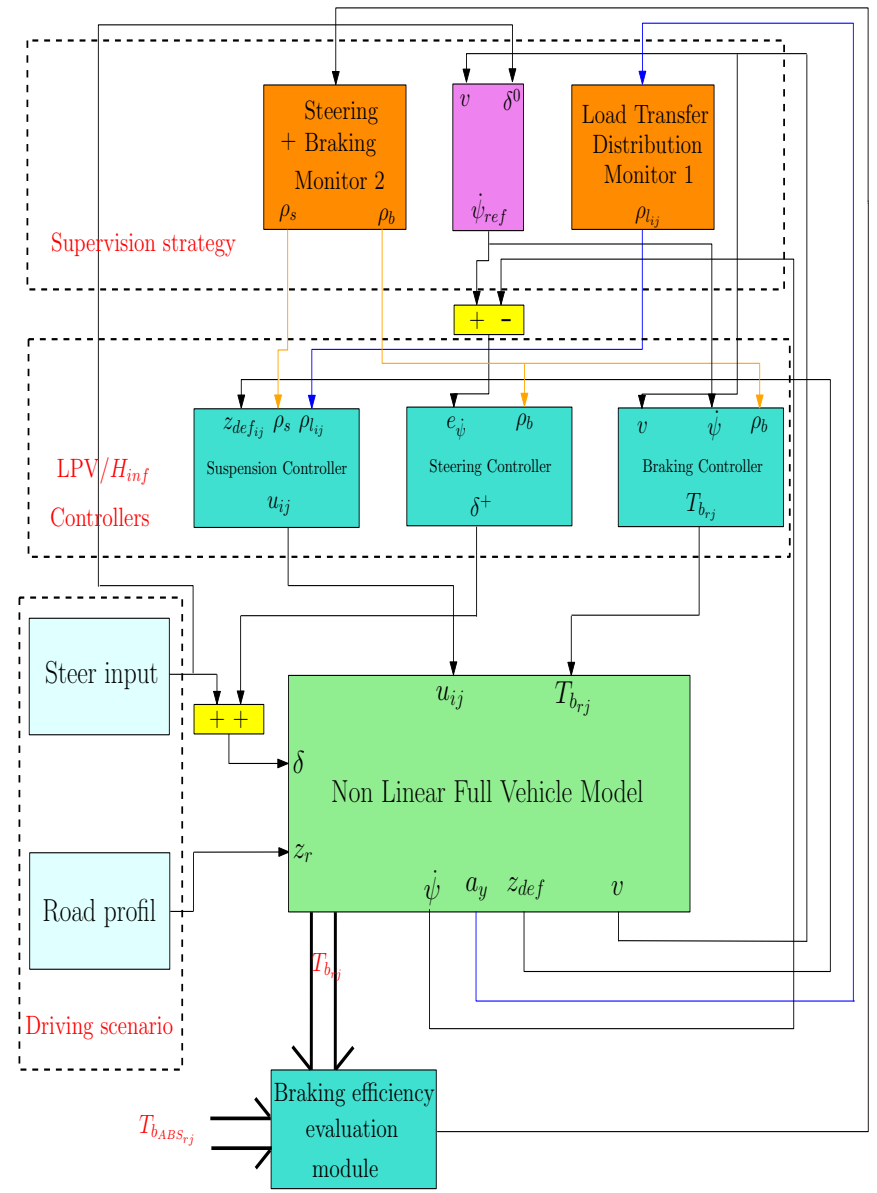

Fig. 10. Global chassis control implementation scheme.

performances are changed from soft to hard, in order to handle the dynamical problem. First, in a normal situation, only the suspension acts in order to keep the driving comfort, while not deteriorating the road handling (i.e soft suspension damping). When a dangerous situation is detected through the braking monitor $\rho_{b}$ (in terms of tire slip), the braking torque is limited accordingly in order to bring back the tire forces into the linear stable zone of the tire characteristic and avoid slipping.

The monitoring strategy presented below has been introduced by the authors in [77]. Since attitude and yaw stability are concerned in this study, the strategy based on the measurement of the longitudinal slip ratio of the rear wheels $\left(s_{r j}\right)$ is efficient while being simple. Both scheduling parameters are defined as follows:

- Monitor on the braking efficiency: The aim of the monitor is to schedule the GCC control to activate the steering system when braking is no longer efficient enough to guarantee safety. Then, one proposes the following scheduling strategy:

$$
\rho_{b}=\max \left(\left|e_{T_{b_{r j}}}\right|\right), j=\{l, r\}
$$

where $e_{T_{b_{r j}}}=T_{b_{A B S_{r j}}}-T_{b_{r j}}^{*}$, and one defines the 
scheduling parameter $\xi(e)$ as:

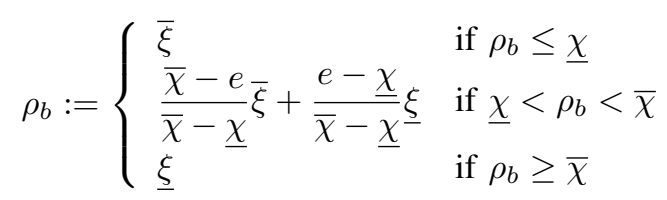

where $\underline{\chi}=\frac{30}{100} T_{b_{\max }}$ and $\bar{\chi}=\frac{70}{100} T_{b_{\max }}$ are user defined brake efficiency measures. Note that other monitor strategies may be employed.

- Suspension and Steering monitor according to the braking efficiency: $\rho_{s}$ is defined as :

$$
\rho_{s} \begin{cases}\rightarrow 1 & \text { when } 1>\rho_{b}>R_{\text {crit }}^{2} \\ =\frac{\rho_{b}-R_{\text {crit }}^{1}}{R_{\text {crit }}^{2}-R_{\text {crit }}^{1}} & \text { when } R_{\text {crit }}^{1}<\rho_{b}<R_{\text {crit }}^{2} \\ \rightarrow 0 & \text { when } 0<\rho_{b}<R_{\text {crit }}^{1}\end{cases}
$$

when $\rho_{b}>R_{\text {crit }}^{2}(=0.9)$, i.e. when a low $\operatorname{slip}\left(<s^{-}\right)$ is detected, the vehicle is not in an emergency situation and $\rho_{s}$ is set to 0 . When $\rho_{b}<R_{c r i t}^{1}(=0.7)$, i.e. when a high slip occurs $\left(>s^{+}\right)$, a critical situation is reached and $\rho_{s}$ is set to 0 . Intermediate values of $\rho_{b}$ will give intermediate driving situations.

In the design step we will see how these parameters allow to handle critical situations through the activation of steering/braking actuators and through the adaptation of the active suspension performances (to mitigate the roll movement).

2) Control reconfiguration under damper malfunction: We propose a real-time adaptation of the right/left suspension control distribution when a damper malfunction is detected (that will generate a lateral load transfer and increase the risk of roll-over). Indeed, the load transfer caused by roll motion is considerably affected by the suspension system behaviour. The suspension systems efficiency can be monitored through different strategies (leakage sensors, observers, parity space,...), but since the induced effect on vertical dynamics can be seen directly on the lateral load transfer of the vehicle, a smart way to get benefit from that and simplify the control structure is to consider the following varying parameter:

$$
\left\{\begin{aligned}
F_{z_{l}}= & m_{s} \times g / 2+m_{s} \times h \times a_{y} / l_{f} \\
F_{z_{r}}= & m_{s} \times g / 2-m_{s} \times h \times a_{y} / l_{r} \\
\rho_{l}= & \left|\left(\delta_{f l} F_{z_{f l}}+\delta_{r l} F_{z_{r l}}\right)-\left(\delta_{f r} F_{z_{f r}}+\delta_{r r} F_{z_{r r}}\right)\right| \\
& /\left|\left(F_{z_{f l}}+F_{z_{r l}}+F_{z_{f r}}+F_{z_{r r}}\right)\right| ;
\end{aligned}\right.
$$

$\delta_{i j}$ : the suspension systems efficiency, $F_{z_{i j}}$ : the vertical forces, $a_{y}$ lateral acceleration, $\rho_{l} \in\left[\begin{array}{ll}0 & 1\end{array}\right]$ : the monitoring parameter.

To manage the suspension control distribution in case of damper malfunction, we propose an innovative partly fixed structure of controller, by making the LMIs structure orthogonal with a parameter dependency on the control output matrix, as follows:

$$
\left(\begin{array}{c}
u_{f l}^{\mathcal{H}}(t) \\
u_{\infty}(t) \\
u_{\infty}(t) \\
u_{r l}^{\mathcal{H}}(t) \\
u_{r r}^{\mathcal{H}}(t)
\end{array}\right)=\underbrace{U\left(\rho_{l}\right) C_{c}^{0}\left(\rho_{l}\right)}_{C_{c}\left(\rho_{l}\right)} x_{c}(t)
$$

The suspension forces distribution is obtained through the matrix $U\left(\rho_{l}\right)$ :

$$
U\left(\rho_{l}\right)=\left(\begin{array}{cccc}
1-\rho_{l} & 0 & 0 & 0 \\
0 & \rho_{l} & 0 & 0 \\
0 & 0 & 1-\rho_{l} & 0 \\
0 & 0 & 0 & \rho_{l}
\end{array}\right)
$$

The parameter $\rho_{l}$ as defined in (26) allows to generate the adequate suspension forces in the four corners of the vehicle depending on the load transfer (left $\leftrightarrows$ right) caused by the performed driving scenario.

This suspension tuning is achieved as follows: when one of the suspension dampers is faulty, the generated load transfer will influence the vehicle stability and handling. For instance, when a malfunction is detected on the left front suspension system, $\rho_{l} \rightarrow 1$ penalizing the provided output suspension force on the faulty corner changing the level of saturation depending on the detected fault. Also, an overload appears on the right side. To managed that, the lacking suspension effort is compensated by the 3 healthy dampers to stabilise the vehicle. Indeed, left suspension are set to be "hard" to handle the overload caused by the loss of one of the right side dampers. On the other side, suspensions are relaxed and tuned to be "soft" for the remaining healthy actuators and a level of saturation is applied to the faulty one depending of the degree of deterioration detected.

\section{B. Global chassis control design}

The synthesis of the different controllers is completed in 2 steps, to decouple lateral and vertical dynamics. The coupling effects are handled through the scheduling parameter $\rho_{s}$ and thanks to an "anti-roll" action of the active suspension.

- First the steering/braking controllers are designed using the linear bicycle model, to improve the lateral dynamics and to stabilize the vehicle.

- Then the suspension controllers are synthesized, using the linear vertical full car model, to improve the comfort/road handlding performance objectives and the vertical dynamics behavior.

26) Remark 2: It should be noted that, while in [77] only the braking action (scheduled by $\rho_{b}$ ) is used only, the lateral dynamics are controlled here using both the braking and steering actions (as in [16]), scheduled by $\rho_{b}$ and $\rho_{s}$ respectively.

Below, LPV/H $\mathcal{H}_{\infty}$ controllers (with $\rho_{b}$ and $\rho_{s}$ the scheduling parameters) are developed thanks to a dedicated polytopic approach.

a) step 1: the braking/steering control Problem formulation: Let us introduce first the extended bicyle model (29).

The considered LPV/H $\mathcal{H}_{\infty}$ control problem is described in Fig. (11) with the following scheduled weighting functions: 


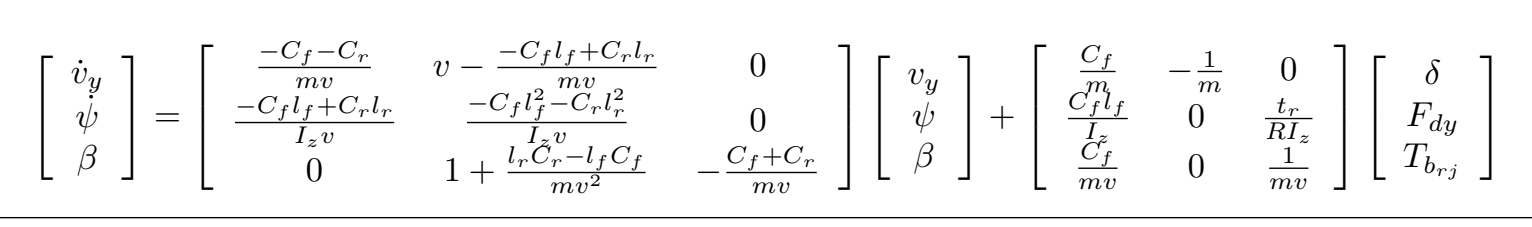

- $W_{e_{\dot{\psi}}}=10 \frac{s / 500+1}{s / 50+1}$, is used to shape the yaw rate error

- $W_{\dot{v}_{y}}=10^{-3}$, attenuates the lateral acceleration

- $W_{T_{b_{r j}}}\left(R_{b}\right)=\left(1-\rho_{b}\right) \frac{s / 10 \varpi+1}{s / 100 \varpi+1}$, attenuates the yaw moment control input

- $W_{\delta^{0}}\left(\rho_{s}\right)=\rho_{s} \frac{s / \kappa+1}{s / 10 \kappa+1}$, attenuates the steering control input according to the value of $\rho_{s}$

where $\varpi$ (resp. $\kappa$ ) is the braking (resp.steering) actuator cut-off frequency.

- When the tire force is in the linear zone, i.e. there is no risk of locking; so $\rho_{b} \rightarrow 1$ and the weighting function gain of $W_{T_{b_{r j}}}$ is chosen to be low. Therefore, the braking control is activated.

- When a high slip ratio is detected (critical situation), the tire may lock, so $\rho_{b} \rightarrow 0$ and the gain of the weighting function is set to be high. This allows to deactivate the braking signal leading to a natural stabilisation of the slip dynamic.

On the other hand, when the driving situation is dangerous and presents a high risk for passengers, the steering control is activated through $W_{\delta^{0}}\left(\rho_{s}\right)$. The steering action depends on the varying parameter $\rho_{s}$, with $\rho_{s}(.) \in \mathcal{P}_{\rho_{s}}$ and $\mathcal{P}_{\rho_{s}}:=$ $\left\{\rho_{s} \in \mathbb{R}: \underline{\rho_{s}} \leq \rho_{s} \leq \overline{\rho_{s}}\right\}$ (where $\underline{\rho_{s}}=0.1$ and $\overline{\rho_{s}}=1$ ).

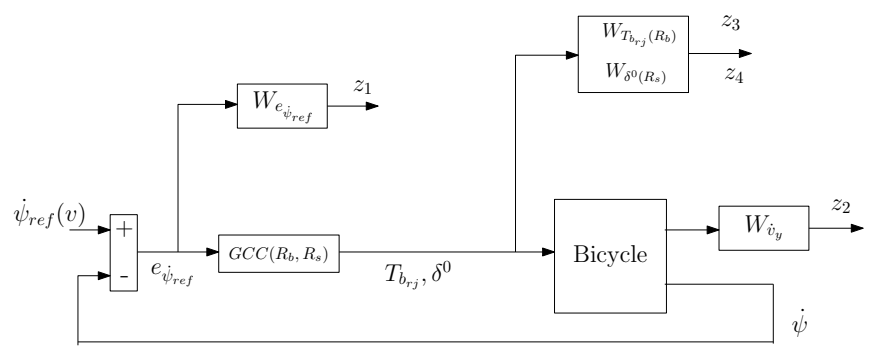

Fig. 11. Generalized plant for braking/steering control synthesis.

The generalized plant corresponding to Fig. 11 is LPV and can be modeled as,

$\Sigma(R()):.\left[\begin{array}{c}\dot{x} \\ \hline z \\ y\end{array}\right]=\left[\begin{array}{c|cc}A(\rho(.)) & B_{1}(\rho(.)) & B_{2} \\ \hline C_{1}(\rho(.)) & D_{11}(\rho(.)) & D_{12} \\ C_{2} & 0 & 0\end{array}\right]\left[\begin{array}{c}x \\ \hline w \\ u\end{array}\right]$

where $x$ includes the state variables of the system and of the weighing functions, $w=F_{d y}$ and $u=\left[\delta^{0}, T_{b_{r j}}\right]$ are the exogenous and control inputs respectively; $z=\left[z_{1}, z_{2}, z_{3}, z_{4}\right]=$ $\left[W_{e_{\dot{\psi}}} e_{\dot{\psi}}, W_{\dot{v}_{y}} \dot{v}_{y}, W_{T_{b_{r j}}}\left(\rho_{b}\right) T_{b_{r j}}, W_{\delta^{0}}\left(\rho_{s}\right) \delta^{0}\right]$ holds for the controlled output, and $y=\dot{\psi}_{\text {ref }}(v)-\dot{\psi}$ is the controller input $\left(\dot{\psi}_{r e f}(v)\right.$ is provided by a reference bicycle model as the one described in (29)).

Notice that the LPV model (30) is affine w.r.t parameters $\rho_{s}$ and $\rho_{b}$ and can be described as a polytopic system, i.e. a convex combination of the systems defined at each vertex formed by $\mathcal{P}_{\rho}($.$) , namely \Sigma(\rho()$.$) and \Sigma(\overline{\rho(.)})$.

b) step 2: the suspension control problem formulation: In this study, a 7 DOF vehicle model is considered, see (32). For the control design purposes, the suspension forces are modeled as follow:

$$
F_{s_{i j}}=k_{i j}\left(z_{s_{i j}}-z_{u s_{i j}}\right)+c_{i j}\left(\dot{z}_{s_{i j}}-\dot{z}_{u s_{i j}}\right)+u_{i j}^{\mathcal{H}}
$$

where $k_{i j}$ represents the stiffness coefficient of the suspension (that includes the spring element), $c_{i j}$ is the nominal damping coefficient and $u_{i j}^{\mathcal{H} \infty}$ the control input (where $k_{*}$ and $c_{*}$ are assumed linear in the control design step).

The suspension control problem with performance adaptation (see [4]), to be integrated in the global VDSC strategy (Vehicle Dynamic Control), is considered using the following $H_{\infty}$ control scheme including parameter varying weighting

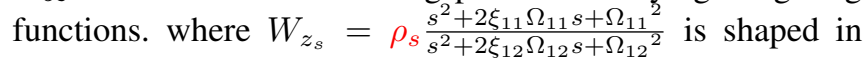

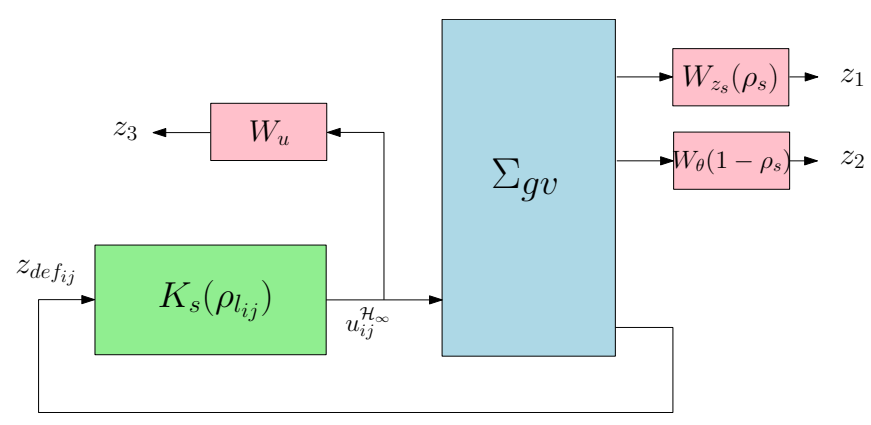

Fig. 12. Suspension system generalized plant.

order to reduce the bounce amplification of the suspended mass $\left(z_{s}\right)$ between $[0,12] \mathrm{Hz}$.

$W_{\theta}=\left(1-\rho_{s}\right) \frac{s^{2}+2 \xi_{21} \Omega_{21} s+\Omega_{21}{ }^{2}}{s^{2}+2 \xi_{22} \Omega_{22} s+\Omega_{22}{ }^{2}}$ attenuates the roll bounce amplification in low frequencies.

$W_{u}=3.10^{-2}$ shapes the control signal.

Remark 3: The parameters of these weighting functions are obtained using genetic algorithm optimization as in [15].

According to Fig. 12, the following parameter dependent suspension generalized plant is obtained:

$$
\left\{\begin{array}{l}
\dot{\xi}=A\left(\rho_{s}, \rho_{l}\right) \xi+B_{1} \tilde{w}+B_{2} u \\
\tilde{z}=C_{1}\left(\rho_{s}, \rho_{l}\right) \xi+D_{11} \tilde{w}+D_{12} u \\
y=C_{2} \xi+D_{21} \tilde{w}+D_{22} u
\end{array}\right.
$$

where $\xi=\left[\begin{array}{ll}\chi_{v e r t} & \chi_{w}\end{array}\right]^{T} ; \tilde{z}=\left[\begin{array}{lll}z_{1} & z_{2} & z_{3}\end{array}\right]^{T}$; $\tilde{w}=\left[\begin{array}{lll}z_{\text {rij }} & F_{d x, y, z} & M_{d x, y}\end{array}\right]^{T} ; y=z_{\text {def }} ; u=u_{i j}^{\mathcal{H} \infty} ;$ and $\chi_{w}$ are the vertical weighting functions states.

One of the main interesting contributions is the use of the parameter $\rho_{l}$ to schedule the distribution of the left \& 


$$
\left\{\begin{aligned}
\ddot{z}_{u s_{i j},} & =\left(F_{s z_{i j}}-F_{t z_{i j}}\right) / m_{u s_{i j}} \\
\ddot{\theta} & =\left(\left(F_{s z_{r l}}-F_{s z_{r r}}\right) t_{r}+\left(F_{s z_{f l}}-F_{s z_{f r}}\right) t_{f}+m h \dot{v}_{y}\right) / I_{x} \\
\ddot{\phi} & =\left(F_{s z_{f}} l_{f}-F_{s z_{r}} l_{r}-m h \dot{v}_{x}\right) / I_{y} \\
\ddot{\psi} & =\left(l_{f}\left(-F_{t x_{f}} \sin (\delta)+F_{t y_{f}} \cos (\delta)\right)-l_{r} F_{t y_{r}}+\left(F_{t x_{f r}}-F_{t x_{f l}}\right) t_{f} \cos (\delta)-\left(F_{t x_{r r}}-F_{t x_{r l}}\right) t_{r}+M_{d z}\right) / I_{z} \\
\dot{\omega}_{i j} & =\left(R_{i j} F_{t x_{i j}}-T_{b_{i j}}^{f}\right) / I_{w}
\end{aligned}\right.
$$

right suspensions on the four corners of the vehicle and tune the suspension dampers smoothly, thanks to the LPV frame work, from "soft" to "hard" to improve the car performances according to the driving situation. This distribution is handled using a specific structure of the suspension controller $K_{s}\left(\rho_{s}, \rho_{l}\right)$, given as follows :

$$
\left\{\begin{array}{l}
\dot{x}_{c}(t)=A_{c}\left(\rho_{s}, \rho_{l}\right) x_{c}(t)+B_{c}\left(\rho_{s}, \rho_{l}\right) y(t) \\
u^{\mathcal{H} \infty}(t)=C_{c}\left(\rho_{s}, \rho_{l}\right) x_{c}(t)
\end{array}\right.
$$

where $x_{c}(t)$ is the controller state, $A_{c}, B_{c}$ and $C_{c}$ controller scheduled by $\rho_{s}$ and $\rho_{l} . u^{\mathcal{H}_{\infty}}(t)=$ $\left[u_{f l}^{\mathcal{H}_{\infty}}(t) u_{f r}^{\mathcal{H}_{\infty}}(t) u_{r l}^{\mathcal{H}_{\infty}}(t) u_{r r}^{\mathcal{H}_{\infty}}(t)\right]$ the input control of the suspension actuators and $y(t)=z_{\text {def }}(t)$.

In this synthesis, the authors wish to stress that an interesting innovation is the use of a partly fixed structure controller with a parameter dependency $\left(\rho_{l}\right)$ on the control output matrix, combined with the use of varying parameter $\rho_{s}$ on the weighting functions of the chassis displacement $\left(z_{s}\right.$, considered as a comfort indicator) and the roll motion ( $\theta$, a road holding indicator). This allows to activate the different actuators depending on the driving situation, and to coordinate efficiently these actuators with smooth transition between different performance objectives even if they are contradictory.

The LPV system (33) includes two single scheduling parameters and can be described as a polytopic system, i.e, a convex combination of the systems defined at each vertex of a polytope defined by the bounds of the varying parameter. The synthesis of the controller is made under the framework of the $\mathcal{H}_{\infty}$ control of polytopic suspensions, (for more details, see [78]).

\section{Simulation Results}

Time domain simulations are performed on the full nonlinear vehicle model given in [77], including also nonlinear tire and suspensions forces. In the sequel, the performances obtained by the proposed gain-scheduled controller, denoted as 'LPV', are analyzed and compared to the Renault Mégane Coupé car (without control denoted as "open Loop").

Here, the scenario considered concerns a vehicle with a fault on the rear left braking actuator.

The vehicle runs at $100 \mathrm{~km} / \mathrm{h}$ on a wet road $(\mu=0.5)$ in straight line. A double line change manoeuvre is performed (from $t=2 \mathrm{~s}$ to $t=6 \mathrm{~s}$ ) by the driver. Lateral wind occurs at vehicle's front generating an undesirable yaw moment (from $t=2.5 \mathrm{~s}$ to $t=3 \mathrm{~s}$ ).

A saturation of $75 \mathrm{~N}$ on the left rear braking actuator is applied to simulate the fault on the braking system. The
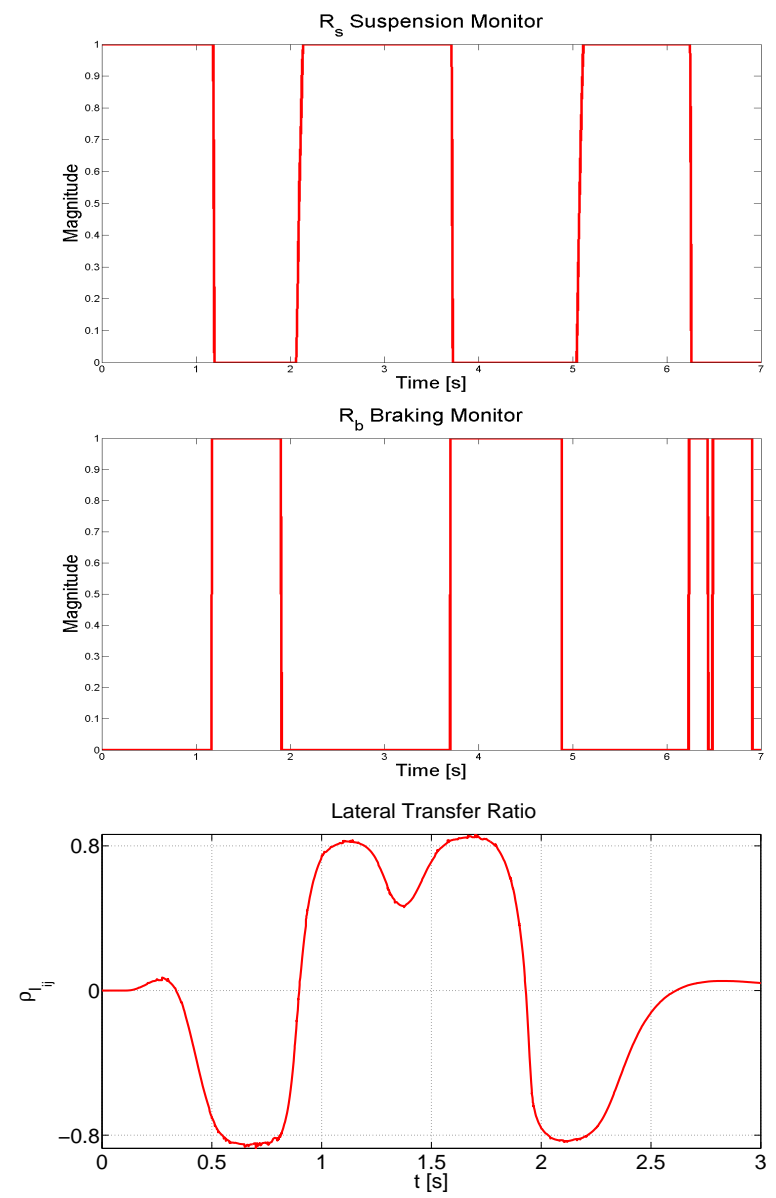

Fig. 13. Monitoring signals

resulting monitoring signals $\rho_{b}$ and $\rho_{s}$ and $\rho_{l}$ are obtained (see Fig. 13).

These parameters allow to activate or deactivate the control actions, when required. Note that $\rho_{b}$ monitors the braking efficiency (compared to an ABS system) and $\rho_{s}$ depends on the value of $\rho_{b}$. It also provides the needed assistance to the driver by giving an additional steering $\delta^{+}$and setting the suspension dampers to "hard" to enhance road handling in critical situations. Also $\rho_{l}$ allows to distribute the suspension efforts depending on load transfer left/right to manage the overload on each corner of the vehicle by generating the adequate efforts.

It can be seen from Fig. 14 that the proposed strategy enhances the vehicle lateral stability. The vehicle yaw rate is considerably enhanced by the LPV approach, which improves the car lateral dynamics. 


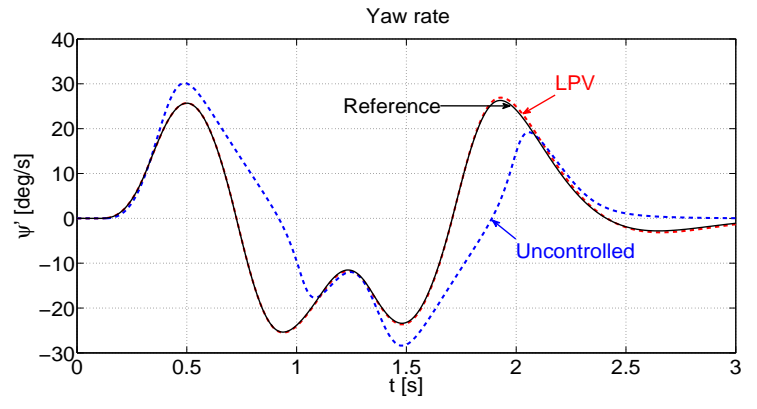

Fig. 14. Yaw rate

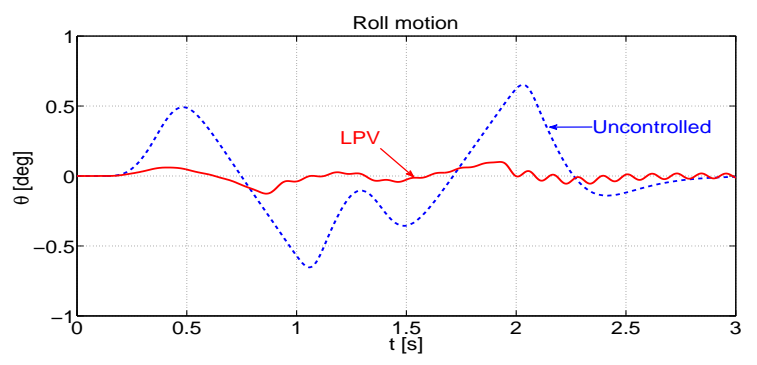

Fig. 15. Roll motion of the chassis

Remark 4: For Fig. 14, a "reference vehicle" yaw rate is given to have a better idea on the improvement brought by the proposed LPV strategy.

Fig. 15 shows that the LPV design strategy, in addition of enhancing vehicle stability, improves the vertical dynamics. It can be seen that the roll dynamics are considerably attenuated which enhances the vehicle handling when facing critical driving situations.

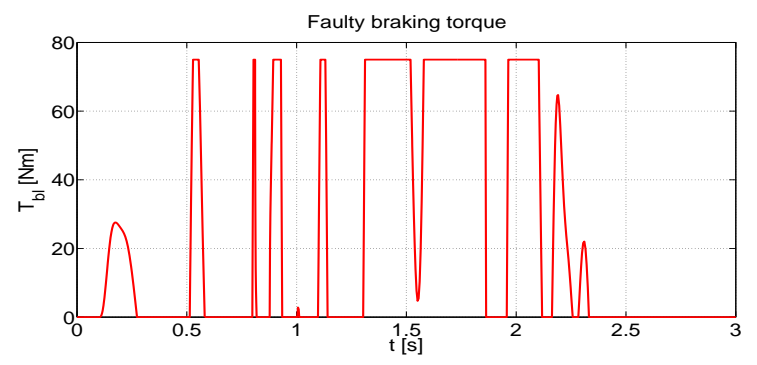

Fig. 16. Rear right Breaking torque.

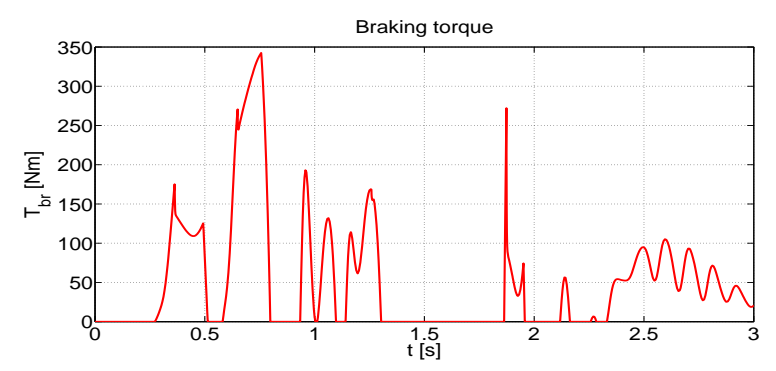

Fig. 17. Rear left Breaking torque.

Fig.16 shows the considered faulty braking torque. It can be clearly seen that the actuators is saturated at low value $(75 \mathrm{Nm})$ which simulates the actuator failure and generate a instability risk.

In Fig. 17 the healthy braking actuator is shown. The torque provided by the right rear actuator is generated by the previously synthesised LPV/H $\mathcal{H}_{\infty}$ to ensure vehicle stability when the driver is performing this dangerous scenario.

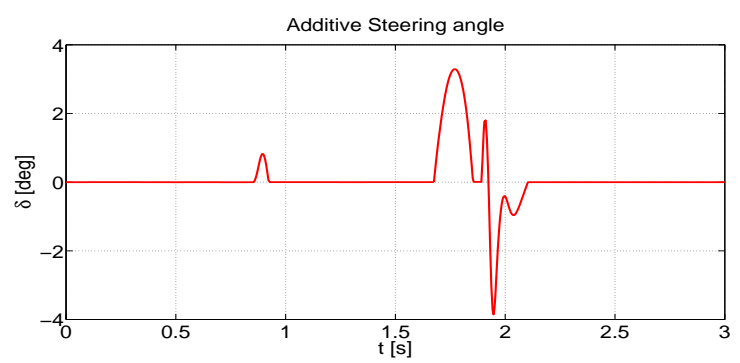

Fig. 18. Steer control input

Fig. 18 shows that the steer control is well coordinated with the braking actuator to compensate the lack of the braking torque on the left rear wheel, (and this will a small contro effort).

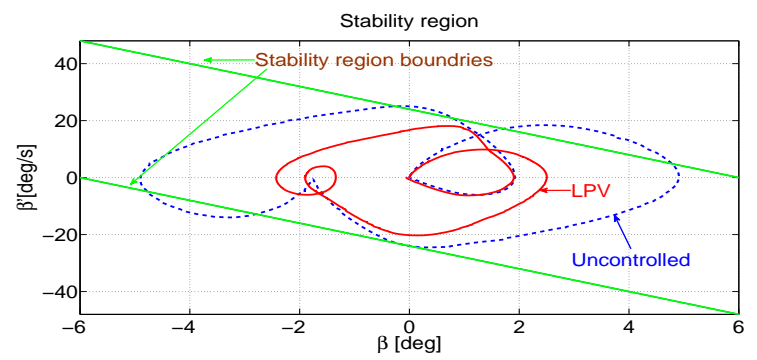

Fig. 19. Stability region creteria

The result in Fig. 19 shows the efficiency of the proposed strategy in term of vehicle stabilization. It can be clearly seen that the good coordination of the vehicle steering, braking and suspension improves very well the vehicle behaviour and enhance the various car dynamics (vertical, lateral...). The vehicle is kept, by the proposed $\mathrm{LPV} / \mathcal{H}_{\infty}$, from going beyond the limits of the stability region (based on the sideslip stability observation of the vehicle) even when performing a dangerous driving situation.

Remark 5: One of the important advantage of the $\mathrm{LPV} / \mathcal{H}_{\infty}$ control is coordinating hierarchically the use of differente actuators to prevent the risk of loss of manoeuvrability and safety degradation in critical driving conditions.

\section{CONCLUding REMARKS}

In that paper, the interest of the LPV approach, not only to deal with non linear plant models, but also to account for actuator malfunctions, has been emphasized in two application cases. First in the case of semi-active suspension control with possible damper malfunction, the actuator efficiency is estimated and considered as a scheduling parameter to provide a FTC LPV suspension control strategy with fault 
scheduling performances. In the second case, a LPV yaw controller is designed using front steering, rear braking and four active suspension actuators. The proposed LPV strategy allows to handle the effects of braking and suspension actuator malfunctions. Indeed a smart LPV control structure is proposed that allows to provide control reconfiguration thanks to the coordination of all the actuators.

When a FDD scheme is available, the LPV approach is then shown to be a nice tool to derive reconfigurable control with:

- fault-scheduling control design in order to ensure fault compensation,

- fault-adaptive performances to satisfy the actuator constraints and to provide desired performance degradation,

- fault-accommodation MIMO control to modify on-line the control allocation.

\section{REFERENCES}

[1] U. Kiencke and L. Nielsen, Automotive Control Systems, SpringerVerlag, Ed., 2000.

[2] T. Gillespie, Fundamental of vehicle dynamics, S. of Automotive Engineers, Ed. Society of Automotive Engineers, Inc, 1992.

[3] O. Sename, P. Gaspar, and J. E. Bokor, Robust Control and Linear Parameter Varying Approaches: application to Vehicle Dynamics, ser. Lecture Notes in Control and Information Sciences. Springer Berlin Heidelberg, 2013, vol. 437.

[4] S. Savaresi, C. Poussot-Vassal, C. Spelta, O. Sename, and L. Dugard, Semi-Active Suspension Control Design for Vehicles. Elsevier Butterworth Heinemann, 2010.

[5] A. Zin, "Robust automotive suspension control toward global chassis control," PhD Thesis (in French), INPG, Laboratoire d'Automatique de Grenoble (new GIPSA-lab), Grenoble, France, October 2005.

[6] M. Tanelli, "Active braking control systems design for road vehicles," $\mathrm{PhD}$ Thesis, Politecnico di Milano, dipartimento di Elettronica e Informazione, Milano, Italy, May 2007.

[7] C. Poussot-Vassal, "Robust Multivariable Linear Parameter Varying Automotive Global Chassis Control," PhD Thesis, Grenoble INP, GIPSA-lab, Control System dpt., Grenoble, France, September 2008.

[8] M. Corno, "Active stability control systems design for road vehicles," Ph.D. dissertation, POLITECNICO DI MILANO, Dipartimento di Elettronica e Informazione, 2009.

[9] S. Aubouet, "Semi-active soben suspensions modeling and control," $\mathrm{PhD}$ Thesis, Université de Grenoble, GIPSA-lab, Grenoble, France, October 2010.

[10] A. L. Do, "Lpv approach for semi-active suspension control: Joint improvement of comfort and security," PhD Thesis, INPG, GIPSAlab, Grenoble, France, October 2011.

[11] J. Lunze and J. Richter, "Reconfigurable fault-tolerant control: A tutorial introduction," European Journal of Control, vol. 14, no. 5, pp. $359-386,2008$.

[12] Y. Zhang and J. Jiang, "Bibliographical review on reconfigurable faulttolerant control systems," Annual Reviews in Control, vol. 32, no. 2, pp. $229-252,2008$.

[13] C. Poussot-Vassal, O. Sename, L. Dugard, P. Gáspár, Z. Szabó, and J. Bokor, "A New Semi-active Suspension Control Strategy Through LPV Technique," Control Engineering Practice, vol. 16, no. 12, pp. 1519-1534, December 2008.

[14] A. L. Do, O. Sename, and L. Dugard, "An LPV control approach for semi-active suspension control with actuator constraints," in Proceedings of the IEEE American Control Conference (ACC), Baltimore, Maryland, USA, June 30 - July 2 2010, pp. 4653 - 4658.

[15] — " "LPV modelling and control of semi-active dampers in automotive systems," in Control of Linear Parameter Varying Systems with Applications, J. Mohammadpour and C. Scherer, Eds. Springer, 2012, ch. 15 .

[16] C. Poussot-Vassal, O. Sename, L. Dugard, and S. M. Savaresi, "Vehicle dynamic stability improvements through gain-scheduled steering and braking control," Vehicle System Dynamics, vol. 49:10, pp. 1597-1621, March 2011
[17] M. Doumiati, O. Sename, L. Dugard, J.-J. Martinez-Molina, P. Gaspar, and Z. Szabo, "Integrated vehicle dynamics control via coordination of active front steering and rear braking," European Journal of Control, vol. 19 , no. 2, pp. $121-143,2013$.

[18] A. Zin, O. Sename, M. Basset, L. Dugard, and G. Gissinger, "A nonlinear vehicle bicycle model for suspension and handling control studies," in Proceedings of the IFAC Conference on Advances in Vehicle Control and Safety (AVCS), Genova, Italy, october 2004, pp. 638-643.

[19] M. Blanke, R. Izadi-Zamanabadi, S. Bogh, and C. Lunau, "Faulttolerant control systems - a holistic view," Control Engineering Practice, vol. 5, no. 5, pp. 693 - 702, 1997.

[20] J.-C. Ponsart, D. Theilliol, and C. Aubrun, "Virtual sensors design for active fault tolerant control system applied to a winding machine," Control Engineering Practice, vol. 18, no. 9, pp. 1037 - 1044, 2010.

[21] G. J. Balas, "Fault tolerant control and fault detection/isolation design for linear parameter varying systems," International Journal of Adaptive Control and Signal Processing, vol. 26, no. 3, pp. 189-189, 2012. [Online]. Available: http://dx.doi.org/10.1002/acs.2276

[22] D. Henry, "Design of norm based fault detection and isolation lpv filters," in Robust Control and Linear Parameter Varying Approaches, ser. Lecture Notes in Control and Information Sciences, O. Sename, P. Gaspar, and J. Bokor, Eds. Springer Berlin Heidelberg, 2013, vol. 437, pp. $125-182$

[23] A. Abdullah and M. Zribi, "Sensor-fault-tolerant control for a class of linear parameter varying systems with practical examples," Industrial Electronics, IEEE Transactions on, vol. 60, no. 11, pp. 5239-5251, 2013.

[24] R. J. Patton, L. Chen, and S. Klinkhieo, "An lpv pole-placement approach to friction compensation as an ftc problem," Int. J. Appl. Math. Comput. Sci., vol. 22, no. 1, pp. 149-160, March 2012.

[25] S. Montes de Oca, V. Puig, and J. Blesa, "Robust fault detection based on adaptive threshold generation using interval lpv observers," International Journal of Adaptive Control and Signal Processing, vol. 26, no. 3, pp. 258-283, 2012. [Online]. Available: http://dx.doi.org/10.1002/acs.1263

[26] M. Hamayun, H. Alwi, and C. Edwards, "An lpv fault tolerant control scheme using integral sliding modes," in Decision and Control (CDC), 2012 IEEE 51st Annual Conference on, 2012, pp. 1840-1845.

[27] R. Nazari, M. Seron, and J. D. Dona, "Fault-tolerant control of systems with convex polytopic linear parameter varying model uncertainty using virtual-sensor-based controller reconfiguration," Annual Reviews in Control, vol. 37, no. 1, pp. 146 - 153, 2013.

[28] S. de Oca and V. Puig, "Fault-tolerant control design using a virtual sensor for lpv systems," in Control and Fault-Tolerant Systems (SysTol), 2010 Conference on, 2010, pp. 88-93.

[29] S. de Oca, V. Puig, D. Theilliol, and S. Tornil-Sin, "Fault-tolerant control design using lpv admissible model matching with h2/hinf; performance: Application to a two-degree of freedom helicopter," in Control and Fault-Tolerant Systems (SysTol), 2010 Conference on, 2010, pp. 251-256.

[30] C. Sloth, T. Esbensen, and J. Stoustrup, "Robust and fault-tolerant linear parameter-varying control of wind turbines," Mechatronics, vol. 21 , no. 4 , pp. $645-659,2011$.

[31] B. Németh, P. Gaspar, J. Bokor, O. Sename, and L. Dugard, "Faulttolerant control design for trajectory tracking in driver assistance systems," in 8th IFAC Symposium on Fault Detection, Supervision and Safety of Technical Processes, 2012, pp. 186-191.

[32] H. Niemann and J. Stoustrup, "An architecture for fault tolerant controllers," International Journal of Control, vol. 78, no. 14, pp. 1091-1110, 2005

[33] M. Seron, X. Zhuo, J. D. Dona, and J. Martinez, "Multisensor switching control strategy with fault tolerance guarantees," Automatica, vol. 44 , no. 1 , pp. 88-97, 2008.

[34] J. Jiang and X. Yu, "Fault-tolerant control systems: A comparative study between active and passive approaches," Annual Reviews in Control, vol. 36, no. 1, pp. 60 - 72, 2012.

[35] Y. Shen, L. Liu, and E. Dowell, "Adaptive fault-tolerant robust control for a linear system with adaptive fault identification," Control Theory Applications, IET, vol. 7, no. 2, pp. -, 2013.

[36] L. Liu, Y. Shen, E. H. Dowell, and C. Zhu, "A general fault tolerant control and management for a linear system with actuator faults," Automatica, vol. 48, no. 8, pp. 1676 - 1682, 2012.

[37] X. Yu and J. Jiang, "Hybrid fault-tolerant flight control system design 
against partial actuator failures," Control Systems Technology, IEEE Transactions on, vol. 20, no. 4, pp. 871-886, 2012.

[38] P. Gáspár, Z. Szabó, and J. Bokor, "Lpv design of fault-tolerant control for road vehicles," Int. J. Appl. Math. Comput. Sci. (selected from Systol 2010), vol. 22, no. 1, pp. 173-182, March 2012.

[39] C. Poussot-Vassal, O. Sename, and L. Dugard, "A Global Chassis Controller for Handling Improvements Involving Braking and Steering Systems," in Proceedings of the 47th IEEE Conference on Decision and Control, Cancun, Mexico, December 2008, pp. 5366-5371.

[40] J. C. Tudon-Martinez, S. Varrier, R. Morales-Menendez, R. RamirezMendoza, D. Koenig, J.-J. Martinez, and O. Sename, "Fault tolerant control with additive compensation for faults in an automotive damper?" in Networking, Sensing and Control (ICNSC), 2013 10th IEEE International Conference on, 2013, pp. 810-814.

[41] C. Scherer, "A tutorial on the control of linear parameter-varying systems," in ACC American Control Conference, Montreal, Canada, june 2012.

[42] P. Apkarian and P. Gahinet, "A convex characterization of gain scheduled $\mathcal{H}_{\infty}$ controllers," IEEE Transaction on Automatic Control, vol. 40, no. 5, pp. 853-864, may 1995.

[43] C. de Souza and A. Trofino, "Gain scheduled $\mathcal{H}_{2}$ controller synthesis for linear parameter varying systems via parameter-dependent Lyapunov functions," International Journal of Robust and Nonlinear Control, vol. 16, pp. 243-257, november 2005.

[44] P. Gahinet, P. Apkarian, and M. Chilali, "Affine parameter-dependent Lyapunov functions and real parametric uncertainty," IEEE Transaction on Automatic Control, vol. 41, no. 3, pp. 436-442, march 1996.

[45] C. Scherer, P. Gahinet, and M. Chilali, "Multiobjective outputfeedback control via LMI optimization," IEEE Transaction on Automatic Control, vol. 42, no. 7, pp. 896-911, july 1997.

[46] C. Scherer, "Robust mixed control and LPV control with full block scaling," Delft University of Technology, Mechanical Engineering Systems and Control Group, Tech. Rep., 2004.

[47] P. Apkarian, P. Gahinet, and G. Beker, "Self-scheduled $\mathcal{H}_{\infty}$ control of linear parameter-varying systems: A design example," Automatica, vol. 31, no. 9, pp. 1251-1262, 1995.

[48] J. Shamma and M. Athans, "Guaranteed properties of linear parameter varying gain scheduled control systems," Automatica, vol. , pp. 559564, may 1991.

[49] J. Mohammadpour and C. S. (Eds.), Control of Linear Parameter Varying Systems with Applications. Springer, 21012.

[50] W. P. M. H. Heemels, J. Daafouz, and G. Millerioux, "Observerbased control of discrete-time lpv systems with uncertain parameters," Automatic Control, IEEE Transactions on, vol. 55, no. 9, pp. 21302135, 2010.

[51] I. Fialho and G. Balas, "Road adaptive active suspension design using linear parameter varying gain scheduling," IEEE Transaction on Control System Technology, vol. 10, no. 1, pp. 43-54, january 2002.

[52] F. Bruzelius, "Linear parameter-varying systems: an approach to gain scheduling," PhD Thesis, University of Technology of Göteborg, Sweeden, February 2004.

[53] P. Gáspár, I. Szaszi, and J. Bokor, "Design of a robust controller for active vehicle suspension using the mixed $\mu$," Vehicle System Dynamics, vol. 40, no. 4, pp. 193-228, 2003.

[54] A. Zin, O. Sename, P. Gaspar, L. Dugard, and J.Bokor, "Robust lpv - $\mathcal{H}_{\infty}$ control for active suspensions with performance adaptation in view of global chassis control," Vehicle System Dynamics, vol. 46, no. 10 , pp. 889-912, 2008.

[55] J. Magni, "An LFT approach to robust gain scheduling," in 44th IEEE onference on Decision and Control, and the European Control Conference 2005, Seville, Spain, December 2005, pp. 7971-7976.

[56] P. Pellandra, P. Apkarian, H. Tuan, and D. Alazard, "Missile autopilot design via a multi-channel LFT/LPV control method," in Proceedings of the 15th IFAC World Congress (WC), Barcelona, Spain, july 2004.

[57] E. Roche, O. Sename, and D. Simon, "Lpv approaches for varying sampling controldesign: Application to autonomous underwater vehicles," in Robust Control and Linear Parameter Varying Approaches, ser. Lecture Notes in Control and Information Sciences, O. Sename, P. Gaspar, and J. Bokor, Eds. Springer Berlin Heidelberg, 2013, vol. 437, pp. 375-396.

[58] M. Lovera, M. Bergamasco, and F. Casella, "Lpv modelling and identification: An overview," in Robust Control and Linear Parameter Varying Approaches, ser. Lecture Notes in Control and Information Sciences, O. Sename, P. Gaspar, and J. Bokor, Eds. Springer Berlin Heidelberg, 2013, vol. 437, pp. 3-24.
[59] C. W. Scherer, "Lpv control and full block multipliers," Automatica, vol. 37, no. 3, pp. 361-375, 2001.

[60] P. Apkarian, P. Gahinet, and G. Becker, "Self scheduled $\mathcal{H}_{\infty}$ control of linear parameter-varying systems: a design method," Automatica, vol. 31 , no. 9, pp. 1251-1261, 1993.

[61] P. Apkarian and R. Adams, "Advanced gain-scheduling techniques for uncertain systems," IEEE Transactions on Automatic Control, vol. 6, pp. 21-32, 1998.

[62] A. Packard, "Gain scheduling via linear fractional transformations," Systems and Conrol Letters, vol. 22, pp. 79-92, 1994.

[63] J. Biannic, "Robust control of parameter varying systems: aerospace applications," PhD Thesis (in French), Université Paul Sabatier (ONERA), Toulouse, France, October 1996.

[64] D. Robert, O. Sename, and D. Simon, "An $H_{\infty}$ LPV design for sampling varying controllers : experimentation with a $\mathrm{t}$ inverted pendulum," IEEE Trans. on Control Systems Technology, vol. 18, no. 3, pp. 741-749, 2010.

[65] C. Poussot-Vassal, O. Sename, and L. Dugard, "Robust Vehicle Dynamic Stability Controller Involving Steering and Braking Systems," in Proceedings of the 9th European Control Conference, Budapest, Hungary, August 2009.

[66] C. Poussot-Vassal, C. Spelta, O. Sename, S. M. Savaresi, and L. Dugard, "Survey and Performance Evaluation on Some Automotive Semi-Active Suspension Control Methods: a Comparative Study on a Single-Corner Model," Annual Review of Control, vol. 36, no. 1.

[67] A. L. Do, C. Spelta, S. Savaresi, O. Sename, L. Dugard, and D. Delvecchio, "An LPV control approach for comfort and suspension travel improvements of semi-active suspension systems," in Proceedings of the 49th IEEE Conference on Decision and Control (CDC), Atlanta, GA, December 2010, pp. 5660-5665.

[68] A. Yetendj, M. Seron, and J. D. Dona, "Diagnosis and actuator fault tolerant control in vehicle active suspension," in 5th International Conference on Information and Automation for Sustainability ICIAFS'07.

[69] A. Chamseddine and H. Noura, "Control and sensor fault tolerance of vehicle active suspension," Control Systems Technology, IEEE Transactions on, vol. 16, no. 3, pp. 416-433, 2008.

[70] S. Guo, S. Yang, and C. Pan, "Dynamic modeling of magnetorheological damper behaviors," Journal of Intelligent Material Systems And Structures, vol. 17, pp. 3-14, January 2006.

[71] J. Lozoya-Santos, R. Morales-Menendez, R. Ramirez-Mendoza, J. Tudón-Martínez, O. Sename, and L. Dugard, "Magnetorheological damper - an experimental study," Journal of Intelligent Material Systems And Structures, vol. 23, pp. 1213-1232, 2012.

[72] S. Varrier, D. Koenig, and J. Martinez, "Robust fault detection for vehicle lateral dynamics," in Proceedings of the 51th IEEE Conference on Decision and Control (CDC), Maui, Hawaii, USA, December 2012.

[73] S. Fergani, O. Sename, and L. Dugard, "Performances improvement through an $\mathrm{LPV} / \mathcal{H}_{\infty}$ control coordination strategy involving braking, semi-active suspension and steering systems," in Proceedings of the 51th IEEE Conference on Decision and Control (CDC), Maui, Hawaii, USA, December 2012.

[74] —, "A LPV/H $\mathcal{H}_{\infty}$ global chassis controller for performances improvement involving braking, suspension and steering systems," in Proceedings of the 7th IFAC Symposium on Robust Control Design, Aalborg, Denmark, June 2012.

[75] _ - "A new LPV/H $\mathcal{H}_{\infty}$ global chassis control through load transfer distribution and vehicle stability monitoring," in Proceedings of IFAC Joint conference 5th Symposium on System Structure and Control, 11th Workshop on Time-Delay Systems 6th Workshop on Fractional Differentiation and Its Applications, Grenoble, France, February 2013.

[76] _ "A lpv suspension control with performance adaptation to roll behavior, embedded in a global vehicle dynamic control strategy," in Proceedings of the European Control Conference 2013, Zurich, Switzerland, July 17-19 2013.

[77] C. Poussot-Vassal, O. Sename, L. Dugard, P. Gáspár, Z. Szabó, and J. Bokor, "Attitude and handling improvements through gainscheduled suspensions and brakes control," Control Engineering Practice, vol. 19, no. 3, pp. 252-263, March 2011.

[78] C. Scherer, "Mixed $\mathcal{H}_{2} / \mathcal{H}_{\infty}$ control for time-varying and linear parametrically-varying systems," International Journal of Robust and Nonlinear Control, vol. 6, no. 9-10, pp. 929-952, november 1996. 